LESSONS FOR ECOLOGICAL POLICY DESIGN:

A CASE STUDY OF ECOSYSTEM MANAGEMENT

William C. Clark, Dixon D. Jones, and C.S. Holling

RR-80-2

February 1980

Reprinted from Ecological Modelling, volume 7 (1979)

INTERNATIONAL INSTITUTE FOR APPLIED SYSTEMS ANALYSIS Laxenburg, Austria 
Research Reports, which record research conducted at IIASA, are independently reviewed before publication. However, the views and opinions they express are not necessarily those of the Institute or the National Member Organizations that support it.

Reprinted with permission from Ecological Modelling 7:1-53, 1979. Copyright @ 1979 Elsevier Scientific Publishing Company.

All rights reserved. No part of this publication may be reproduced or transmitted in any form or by any means, electronic or mechanical, including photocopy, recording, or any information storage or retrieval system, without permission in writing from the copyright holder. 


\section{FOREWORD}

From the beginnings of its research activities in 1973, the International Institute for Applied Systems Analysis (IIASA) has investigated issues of ecosystem management. Early attention focused on a particular case: the competition between man and an insect (the spruce budworm) for utilization of coniferous forests in the Canadian province of New Brunswick. However, this case was chosen for its ability to shed light on larger and more varied problems of ecosystem management.

The leader of this program of research has been C.S. Holling, who has shared his time with both IIASA and the Institute of Animal Resource Ecology (IARE) at the University of British Columbia, Canada. Many other scientists have participated in the work.

An early volume in the IIASA International Series on Applied Systems Analysis (C.S. Holling, editor, Adaptive Environmental Assessment and Management, Wiley, Chichester, United Kingdom) discusses much of the work, and a future volume in the same series (G. Baskerville, W. Clark, C.S. Holling, D. Jones, and C. Miller, Ecological Policy Design: A Case Study of Forests, Insects, and Managers) will describe its extensions. There is also a brief account for the general reader: Expect the Unexpected: An Adaptive Approach to Environmental Management (IIASA Executive Report 1, 1979; available from IIASA).

In the meantime, this paper describes many of the lessons for ecological policy design that have been learned. Its bibliography lists the IIASA and IARE publications that support the findings.

Roger E. Levien

Director 


\title{
LESSONS FOR ECOLOGICAL POLICY DESIGN: A CASE STUDY OF ECOSYSTEM MANAGEMENT
}

\author{
WILLIAM C. CLARK, DIXON D. JONES and C.S. HOLLING * \\ Institute of Resource Ecology, University of British Columbia, Vancouver, \\ B.C. V6T 1 W5 (Canada) and International Institute for Applied Systems Analysis, \\ A-2361 Luxenburg (Austria)
}

(Received 29 November 1977)

\section{ABSTRACT}

Clark, W.C., Jones, D.D. and Holling, C.S., Lessons for ecological policy design: A case study of ecosystem management. Ecol. Modelling, 7: 1-53.

This paper explores the prospects for combining elements of the ecological and policy sciences to form a substantive and effective science of ecological policy design. This exploration is made through a case study whose specific focus is the management problem posed by competition between man and an insect (the spruce budworm, Choristoneura fumiferana) for utilization of coniferous forests in the Canadian Province of New Brunswick. We used this case study as a practical testing ground in which we examined the relative strengths, weaknesses, and complementarities of various aspects of the policy design process. Where existing approaches proved wanting, we sought to develop alternatives and to test them in turn. In particular, we used a combination of simulation modeling and topological approaches to analyze the space-time dynamics of this ecosystem under a variety of natural and managed conditions. Explicit consideration was given to the development of invalidation tests for establishing the limits of model credibility. An array of economic, social, and environmental indicators was generated by the model, enabling managers and policy makers to evaluate meaningfully the performance of the system under a variety of management proposals. Simplified versions of the models were constructed to accommodate several optimization procedures, including dynamic programming, which produced trial policies for a range of possible objectives. These trial policies were tested in the more complex model versions and heuristically modified in dialogue with New Brunswick's forest managers. We explored the role of utility functions for simplifying and contrasting policy performance measures, paying special attention to questions of time preferences and discounting. Finally, the study was shaped by a commitment to transfer the various models and policy design capabilities from their original academic setting to the desks and minds of the practicing managers and politicians. An array of workshops, model gaming sessions, and nontraditional communication formats was developed and tested in pursuit of this goal.

This paper reports some specific management policies developed, and some general lessons for ecological policy design learned in the course of the study.

\footnotetext{
* Order of authorship was selected by lot.
} 


\section{INTRODUCTION}

This paper reports steps towards the development of a science of ecological policy design. First, we show how a number of mathematical tools can be used in the effective dynamic description of specific ecological systems. These tools range from simulation models to differential equations to topological representations. Second, we show how these descriptive methods can be combined with prescriptive techniques from the policy sciences - techniques of optimization, utility analysis and decision theory. Our central argument is that these various elements, developed in separate fields, can now be combined, amplified and tested as a rigorous science of ecological policy design.

Such a science requires two essential ingredients: a conceptual framework and a coherent methodology. Concepts alone are not sufficient, for if not illuminated and evaluated through a rigorous methodology applied to specific problems, they inevitably lose touch with reality. But even the best of methodologies, if not provided with a framework for identifying key conceptual issues, can lead at best to an aimless proliferation of numbers and, at worst, to more intractable problems created more quickly and efficiently.

The key conceptual issue of ecological policy design is how to cope with the unknown and unexpected. Unexpected events bear on the future of every complex system. Our understanding is always incomplete; substantial ignorance is always guaranteed. The aim of sound ecological policy is not to predict and eliminate future surprises, but rather to design resilient systems which can absorb, survive, and capitalize on unexpected events when they do occur. The appropriate paradigm is not that of fail-safe design, but rather of design which is safe (or "soft") in the inevitable event of its failure (Holling and Clark, 1975; Branscomb, 1977).

The history of resource management, and indeed of the applied sciences in general, has been one of trial-and-error approaches to the unknown. Existing information is mobilized and organized to suggest a trial and the errors, when they are detected, provide additional information for modification of subsequent efforts. Such "failures" provide essential probes into the unknown - probes generating the experience and information upon which new knowledge grows. But the increasingly extensive and intensive nature of our trials now threatens errors larger and more costly than society can afford. This is the dilemma of "hypotheticality" posed by Haefele (1974), who argues that the design of policy is locked in a world of hypothesis because we dare not conduct the trials necessary to test and refine our understanding.

The heart of the policy design problem lies in the way systems we manage respond to unexpected events. This response is directly related to the stability properties of the systems.

A system which is globally stable is admirable for blind trial-and-error experimentation: it will always recover from any perturbation. It is this para- 
digm of an infinitely forgiving Nature that has been assumed implicitly in the past, but if a system has multiple regions of stability, then Nature can seem to play the practical joker rather than the forgiving benefactor. Policies, trials, and management will seem to operate effectively as long as the system remains within known stability domains. However, if the system moves close to a stability boundary, incremental perturbations can precipitate radically altered behavior (Holling, 1973). Even more troublesome, the stability boundaries themselves may contract in response to management activities, again generating sudden changes in behavior (Clark, 1976; Peterman, 1977a). In either event, the real danger is that a past history of policy "success" will often result in sufficient institutional inflexibility to make timely management response to the new condition impossible.

Policy design therefore requires a clear understanding of the resilience and stability properties of ecological systems and the institutional and social systems with which they are linked. Two lines of relevant evidence are now accumulating. The first comes from recent efforts to develop structurally simple differential equation models of complex systems, emphasizing the qualitative form of the functional relationships. Such models have been proposed for ecological systems (Bazykin, 1974; Ludwig et al., 1978), institutional systems (Holling et al., 1976a) and social systems (Haefele and Buerk, 1976). Even these simple structures exhibit extremely rich topologies with multiple stability regions a dominant feature. Different regions of parameter space exhibit different numbers and configurations of these stability regions, suggesting that biological, cultural, or managerial "evolution" of the parameters can indeed cause the stability properties of a managed system to change in quite unanticipated ways.

The second line of evidence comes from empirical studies of specific systems. Preliminary findings have been reported in Holling and Goldberg (1971) and Holling $(1973,1976)$ and a detailed review will be published elsewhere. To summarize, a great variety of examples illustrating instances of multi-equilibria structure and of behavioral shifts among equilibria are documented in the ecological, water resource, engineering and anthropological literature. Among the ecological studies, there are cases concerning freshwater and oceanic fisheries, terrestrial grazing, insect pest, and tropical and temperate forest ecosystems (e.g. Ricker, 1963; Holling, 1973; Noy-Meir, 1975; Southwood, 1976). There is, in addition, a larger range of more anecdotal evidence that is part of the community wisdom of the resource manager. Typical examples are the effectively irreversible development of the Scottish moors after deforestation, the desertification of the Middle East, and the loss of productive land in tropical terrestrial systems as a consequence of extensive and intensive agricultural practices.

In brief, the manager would be prudent to view Mother Nature as less benignly forgiving than deviously mischievous. The ecological systems we seek to manage will more than likely exhibit complex multi-equilibria behavior. The combined effects of an uncertain world and an incomplete under- 
standing of system structure guarantee eventual excursions of the managed world into regions near and beyond its local stability boundaries. A recognition of this problem leads us to seek a science of resilient policy design that explicitly articulates the qualitative stability properties of managed systems and develops and evaluates alternative management approaches which respect those properties.

This paper is one of a series that explores related problems of ecological policy design. Our aim here is to provide an overview of the methodological issues involved. A fuller treatment of the conceptual arguments outlined above can be found in Holling $(1973,1976)$, Holling and Clark (1975), Walters (1975a) and Hilborn et al. (1976). Detailed consideration of certain problems posed by the unknown in descriptive modeling is provided in Ludwig et al. (1978). Finally, specific procedures for the design and evaluation of "safe-failure" policies in an uncertain world are a major focus of Holling (1978) and Yorque et al. (1978).

\section{THE CASE STUDY APPROACH}

A conceptual framework for policy design is meaningless unless a cohesive methodology links it to the constraints and realities of actual management practice. To develop such a methodology and to test the applicability and practical relevance of the resilience concept in policy design, we have chosen to analyze specific case studies typical of large classes of ecological problems.

Several case studies of policy design for ecological management already exist. Those of Conway et al. (1975), Gutierrez et al. (1977) and Kiritani (1977) are representative of recent work, but most of these studies have chosen to focus upon the development of specific solutions to specific problems. They have not been concerned with the critical evaluation of design approaches per se, nor with questions of generality or transferability. Precisely because these broader strategic issues have received so little attention in the past, we have made them the foci of our case studies.

The first requirement for the case studies was to represent a common class of problems not specific to any country, creature or resource. To ensure a realistic confrontation with the constraints imposed by feasibility and implementation considerations, we also looked for problems with an active and troubled management history. We selected cases in which existing management agencies could be involved in the analysis from the beginning, emphasizing policy design with, rather than for, the user. Furthermore, we selected problems in which the ecological issues do not altogether dominate the economic and social ones.

The case study analyses are both descriptive and prescriptive. For descriptive purposes, we wish to combine detailed understanding of some key ecological systems with the more promising developments in modeling - simulation, simplified differential equations and topological approaches. The goal is to capture the essential behavior of the system in a number of different but 
complementary forms so that questions relating to the existence and form of multiple equilibria can be specifically defined and explored.

Yet we are equally concerned with prescription. The descriptive models provide laboratory versions of the real world within which alternative policy prescriptions can be developed and evaluated. Just as our central conceptual interest in multiple equilibria has descriptive relevance, so it has prescriptive significance as well. In a policy sense, our goal is to design resilient or robust policies less sensitive to the unexpecteds and unknowns in every system's future. This has led to the application and testing of a variety of prescriptive methodologies from operations research and management science, including optimization techniques, utility analysis and decision theory. The full combination of the concepts and the descriptive and prescriptive techniques provides the essential building blocks for a new science of ecological policy design. Much of this experience is drawn together in Holling (1978). We will focus here on one of the most fully developed case studies, a forest/insect management problem that involves the spruce budworm and the boreal forests of North America.

The spruce budworm (Choristoneura fumiferana) is the most widely spread destructive forest insect of North America. It ranges from Virginia to Labrador and west across Canada into the Northwest Territories (Davidson and Prentice, 1967). Particularly in the northeastern part of its range the budworm periodically undergoes severe and extensive outbreaks, imposing heavy defoliation and mortality on its preferred hosts, balsam fir (Abies balsamea) and white spruce (Picea glauca). The outbreaks result in major social and economic disruptions and have been the object of intensive research and management efforts since the late 1940's (Morris, 1963; Belyea et al., 1975; Prebble, 1975). The present case study was undertaken as a cooperative venture with the scientists and managers of the Canadian Forest Service's Maritimes Forest Research Centre. A detailed report of the work is forthcoming (Yorque et al., 1978). Rather than reiterate that material, we shall concentrate here on the major lessons learned as we attempted to develop, test, and transfer the methodologies and concepts outlined above. These lessons tended to destroy many of our most treasured myths of ecological analysis and policy design - myths which we, our collaborators and the ecological modeling community have often accepted in the past. We have preserved the central myths to remind us of our errors and provide a convenient focus for the discussion which follows.

\section{PRESCRIPTION AND DESCRIPTION}

Myth: Policy design should begin with an analysis of the decision making environment.

If institutions were immutable, if notions of political and technical feasibility never changed, if ultimate goals were known and universally agreed upon, and if we were designing policy for a specific time and place, the deci- 
sion making environment might be a good place to begin the analysis. However, these conditions are simply not met in reality.

First, our own goals concern not the specific but the general. We emphasize the transferability of concepts and methods to a constellation of problems occurring in various regions. It is true that to give focus we initially concentrate on a specific problem with the name budworm/forest and on one particular region - the Province of New Brunswick in Canada. As the steps of transfer began to take place, it ultimately did become necessary to examine a number of specific institutional settings, but these were pragmatic consessions to give specificity and allow for testing in real world situations. To make transfer a reality, the initial emphasis must be on those elements of the problem which are truly general.

This focus on generality is not possible in an analysis of institutional or decision behavior. The state of knowledge in these fields is still primitively rooted in specific examples. In contrast, the state of knowledge of ecological systems and of ecological processes allows for well-tested analyses that have generality beyond the specific focus. With the need to facilitate transfer, the first requirement is to develop an effective and validated dynamic description of the ecological constraints of the problem. In practice, this means a simulation model which can be used as a kind of "laboratory world" with some confidence that it will be responsive to the exploration of a variety of different policies and their consequences.

There is, however, an even more compelling argument for initially structuring the analysis around the descriptive ecological problem rather than the prescriptive decision problem. Decision systems - whether states or individuals - are by nature and necessity fluid creatures. Perceptions and objectives sporadically change in ways that are scarcely understood and are wholly unpredictable. Such shifts occurred repeatedly in the 3 years of our budworm/ forest studies. New findings on insecticide spraying side effects (Crocker et al., 1976) and unprecedented court decisions on the liabilities and responsibilities of the spraying operators have changed insecticides from a weapon grudgingly accepted for forest protection to a political liability. Detailed consideration of policy alternatives has consequently moved from its former position among middle and senior level civil servants to the provincial and federal cabinets themselves. Unforeseen developments in the international wood processing industry have likewise posed novel technical opportunities and political problems. Because of the descriptive foundation of our analysis in budworm/forest ecology, we could readily respond to these unexpected changes in the decision environment. An analysis based upon a particular version of the decision structure would have been constantly changing, hopelessly out of date, or both.

Finally, it should be pointed out that good policy analysis will almost invariably cause changes in the decision environment and therefore cannot, even in principle, use that environment as a foundation for its efforts. When we began our budworm study, one major goal set by the decision makers was 
to find a policy for reducing forest inventories to a more economically productive level. An early result of the analysis was to show that inventories were already drastically depleted, and there were no long term policies which did not include a reduction of harvest rate and/or the institution of yieldincreasing management. The perceived goals and constraints of the decision makers shifted accordingly and the analysis continued. A similar but happier shift occurred when the analysis showed that certain viruses, which inflict only low mortality on budworm and are therefore largely ignored as possible management tools, might have dramatic potential if applied in coordination with other recognized control measures. The decision response here was an expansion of the perceived feasibility region for policy options.

An ecological policy design program must be based on a generalizable description of the underlying biology if it is to be usefully responsive to inevitable but unpredictable changes in the decision environment and if it is to meet the requirements of transferability across a wide range of decision problems.

\section{THE MODELING PROBLEM}

Myth: The descriptive model should be as comprehensive as possible.

Any model represents an abstraction of reality. The problem is not whether, but what to leave out.

Ecosystem management problems are comprised of an immense array of interacting variables, conflicting objectives and competing actions. Attempts to comprehensively model such complexities are futile. At best they produce models as intricate and unfathomable as the real world. More likely, they founder in a limbo of unending data requirements, impossible "debugging" problems, nonexistent validation criteria, and general ineffectiveness (e.g. Cline, 1961; Shubik and Brewer, 1972; Brewer, 1973; Mar, 1974; Ackerman et al., 1974; Holcomb Research Institute, 1976; Mitchell et al., 1976.) Our experience has suggested the opposite course: to be as ruthlessly parsimonious and economical as possible while still retaining responsiveness to the management objectives and actions appropriate for the problem. The variables selected for system description must be the minimum that will capture the system's essential qualitative behavior in time and space.

The initial steps of bounding the problem determine whether the abstract model will usefully represent that portion of reality relevant to policy design. Key decisions must be made regarding the policy domain, the ecosystem variables, the temporal horizon and resolution, and the spatial extent and resolution to be modeled.

\section{Policy domain}

The policy domain can be defined, or bounded, by specifying the range of acts and indicators to which the dynamic model will be responsive. Particular 
policies and objectives can later be assembled from these components.

It is important to clarify what we will mean by the terms "policy", "acts", "indicators", and "objectives". Objectives are descriptions of desired system behavior. A New Brunswick policy maker might well (albeit wishfully) declare his objectives to be "full employment with low cost harvest even if it requires high quantities of insecticide". That objective could be unique to the specific policy maker but its component indicators are probably not. It is easy to imagine an ardent environmentalist using the same indicators - employment, harvest cost and insecticide quantity - but describing his desired combination of them (i.e. his objective) quite differently. Acts are the physical weapons in the manager's arsenal. They are actual things which he can do, such as cutting trees, killing budworm, building mills, and so on. Finally, policies are the rules or plans by which acts are applied to the system in order to obtain its desired behavior. A policy is something of the form: "when there are so-and-so many budworms, spray insecticide," or "harvest such-and-such a quantity of wood each year". As we use the terms, policies are prescriptions for action and, as such, wholly distinct from descriptions either of intent (objectives composed of indicators) or capability (acts).

The range of acts which have been or potentially could be applied to budworm/forest management is enormous, including the use of insecticides, biological control agents, genetic manipulation, and tree harvesting and planting schemes. Moreover, the acts which now seem to be economically impractical might, with future developments, become feasible. However, the whole range of actions feasible now and imagined for the future fall into three qualitative classes - control of insect numbers, harvest of the trees, and the manipulation of the forest through planting (Baskerville, 1975b). To be responsive to management questions, the descriptive model must allow intervention with any of these classes of acts at any moment in any place. The tactical details of how any specific act is implemented can be dealt with on an ad hoc basis, often outside the simulation model. Similarly, although a large number of performance indicators can be imagined, certain indicators of policy performance are independent of place and time and are of universal interest. These include employment, costs and quantities of wood harvested, timber losses to budworm, and a number of environmental indicators (Bell, 1977b, and below under the discussions of evaluation).

The policy domain resulting from these choices is one bounded between the macro level of provincial economics and the micro level of single stand forest management. By explicitly modeling the provincial forest/insect management system we are capable of interfacing with either of these levels.

\section{Variables}

Even the simplest ecosystem contains thousands of species and potential variables. However, existing knowledge, much of it summarized in Morris 
(1963), has allowed us to capture the strategically relevant part of the system's behavior with a limited subset of these variables.

The principal tree species of the system are birch (Betula sp.), white and black spruce (Picea glauca, P. mariana), balsam fir (Abies balsamea), and a variety of hardwoods (Loucks, 1962). These have a dynamic interaction of their own which is dependent on the influence of budworm. Fir is highly susceptible to damage, white spruce moderately so, black spruce only slightly, and birch and hardwoods not at all. Our rule of parsimony and our strategic level of interest dictate that we lump together the principal budworm hosts, fir and white spruce, into a single dynamic variable expressing the density of susceptible forest and eliminate non-host species from dynamic consideration.

The extensive measure of forest density must be coupled with an intensive measure of tree condition. This is closely linked with present foliage condition that, in conifers, can serve to retain the "memory" of past defoliation stress. Budworm's differential preference for fresh rather than aged needles dictates that this qualitative property be split into two variables, called new and old foliage in the model.

Host tree density and susceptibility to budworm are highly dependent upon forest age structure, as are the economic properties of trees as a crop for man. Consequently, we build a dynamic age class structure into the forest model. Repeated early attempts to treat age structure implicitly and so avoid the extra variables were dismal failures, yielding a model completely incapable of describing observed budworm/forest dynamics.

Between outbreaks the budworm is rare but present, its numbers being controlled by natural enemies such as insectivorous vertebrate predators and parasites. A key feature of,this control is that there exists an upper threshold of budworm numbers which, once exceeded, allows the budworm to "escape" predation and multiply unchecked (Takahashi, 1964; Southwood, 1976). The response of vertebrate and parasite numbers to changes in budworm density is slow compared to the rate of interaction between the budworm and its host trees. As a first simple approximation it therefore seemed justified to model the effects of natural enemies implicitly, without resort to additional state variables.

Finally, weather is a key factor affecting budworm survival and dispersal, and is included as a stochastic driving variable in the model.

From the thousands of potential candidates, we abstract the structure of variables shown in Fig. 1 to model the local dynamics of the budworm/forest system.

Time

An analysis of tree rings (Blais, 1965, 1968) covering eight regions of eastern North America and extending as far back as 1704 provides valuable data on the long term temporal pattern of outbreaks. These data, together with more detailed information on recent outbreaks summarized in Brown 

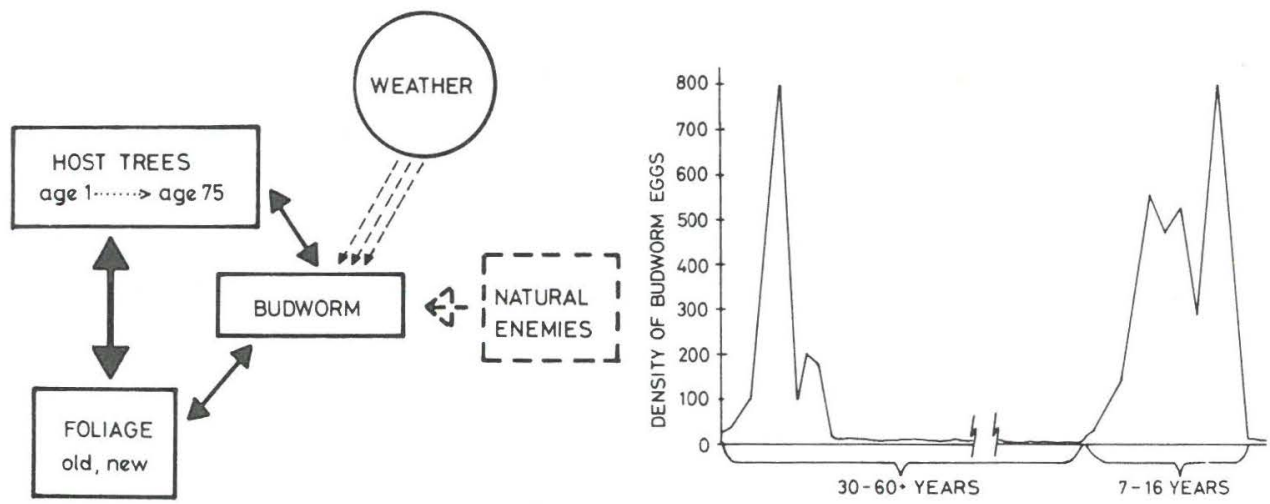

Fig. 1. (Left) Key variables included in the model of the natural ecosystem.

Fig. 2. Temporal outbreak pattern. Schematic portrayal of a typical outbreak cycle. Density is measured as the number per standard $10 \mathrm{ft}^{2}$ balsam fir branch (Morris, 1963). $\left(10 \mathrm{ft}^{2}=0.93 \mathrm{~m}^{2} \simeq 1 \mathrm{~m}^{2}\right.$.)

(1970), indicate a distinctive 30-45 year cycle (Fig. 2). During the inter-outbreak periods the budworm is present in barely detectable numbers that, when appropriate conditions occur, can increase by three orders of magnitude during a 3-4-year period. Once the outbreak is initiated in a sufficiently large area it spreads over thousands of square kilometers, finally collapsing after 7-16 years, often with attendant high mortality to the forest. Because of the pattern of outbreaks shown in Fig. 2, the minimum time horizon required is one which can completely contain two outbreak cycles - that is, between 80 and 160 years.

The time resolution which will capture the dynamics of the system is 1 year - the generation time of the budworm. Seasonal events within the year can be implicitly represented. Equally important, the single year resolution is close to the operational time scale of the management agencies.

Space

The characteristic pattern in time is complemented by one in space. Typically, outbreaks spread from small regions of initiation and contaminate progressively larger areas (Brown, 1970). Collapse of the outbreaks occurs in the original centers of infestation, often in conjunction with severe tree mortality. The result is a high degree of natural spatial heterogeneity in forest age and species composition (Baskerville, 1975a).

The choice of spatial extent for the modeling effort was dictated by the dispersal properties of budworm, data availability, and the concerns of management. As with many pest species, the budworm has very strong dispersal abilities. The modal distance of dispersal is about $40 \mathrm{~km}$, but distances of 
several times this figure have been recorded (Greenbank, 1973). To study the implications of dispersal it was thought essential to model a total area with dimensions of the order of five times this modal distance. The particular area chosen was a $4.5 \times 10^{6}$-ha region containing much of the softwood forest of Canada's Province of New Brunswick (Fig. 3). The peculiar shape is a pragmatic concession to the local management agencies but it does include the majority of the area for which validation and initialization data were available. Analysis efforts subsequent to those reported here have expanded the study area to include most of New Brunswick and substantially reduce the

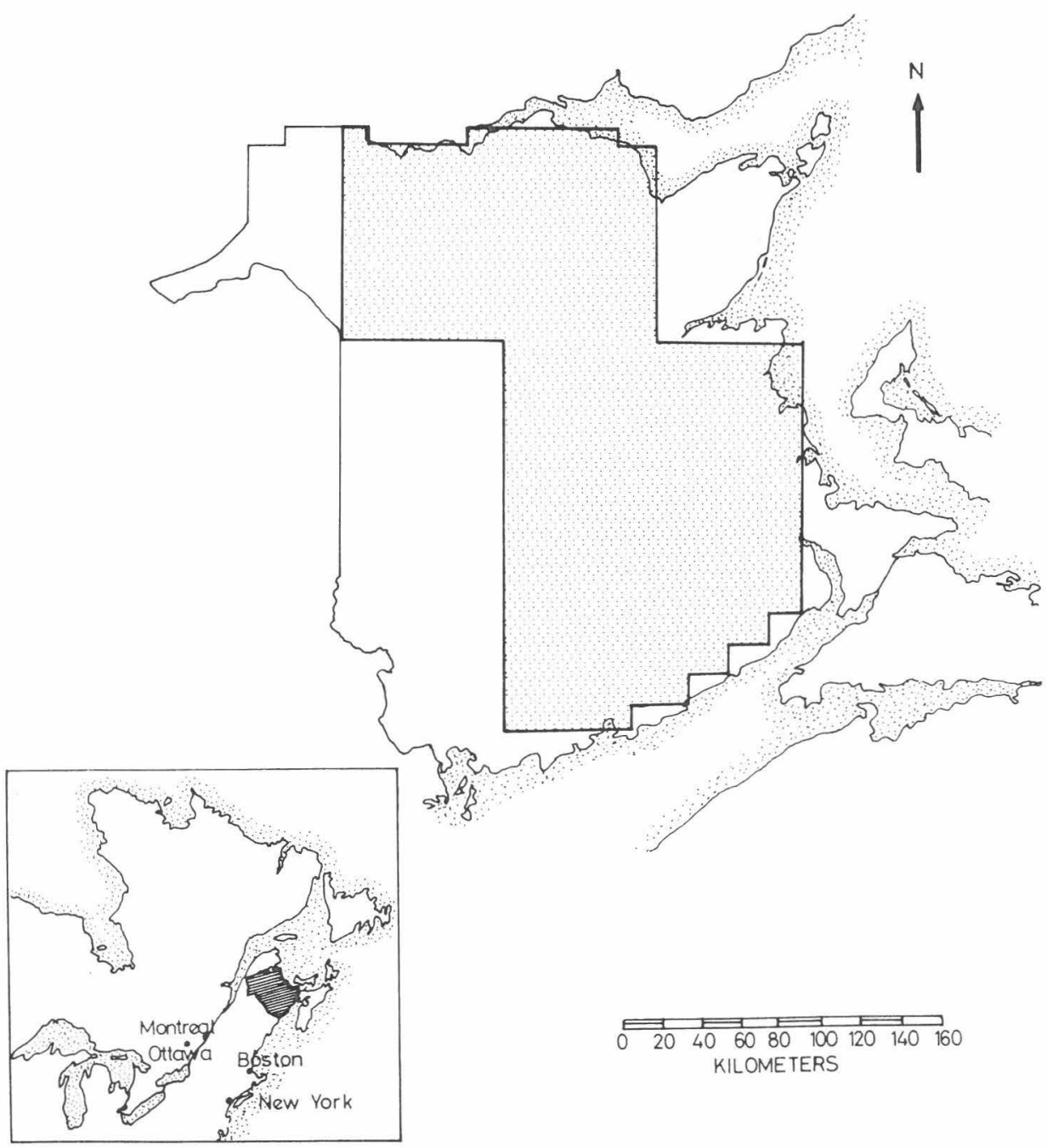

Fig. 3. The modeled area is a $4.5 \times 10^{6}$-ha region comprising most of the softwood forest in the Province of New Brunswick, Canada (see insert). 
edge to volume ratio. A buffer zone approximately $80 \mathrm{~km}$ in width around this area compensates for edge effects.

The spatial resolution of the model is defined by the dispersal capabilities of budworm, the scale of spatial heterogeneity in the forest, and the available data base. The modal dispersal figure of $40 \mathrm{~km}$ dictates a minimum spatial resolution of, at most, half that distance. Since the standard management data unit consists of rectangular grids approximately $11 \times 15 \mathrm{~km}$, the overall region of Fig. 3 was divided into 265 of these biologically arbitrary but convenient spatial units, each containing just over 17,000 ha.

In summary, the decisions on bounding the problem are as follows.

Policy domain. - Responsive to the management acts of insect control, tree harvest and silviculture; generating indicators of employment, costs, harvest, insecticide distribution, environmental quality and timber losses to budworm.

Key variables. - Host tree species (with age structure), foliage condition, budworm density and weather.

Time horizon. - 80-160 years.

Time resolution. -1 year with implicit seasonal causation.

Spatial area. $-4.5 \times 10^{6}$ ha.

Spatial resolution. - 265 subregions of 17,000 ha.

The number of state variables set by this bounding of the problem determines whether or not subsequent prescriptive steps, such as optimization, are feasible. Table I summarizes the final decisions made on the number of state variables required. Even though the previous steps of bounding may seem to have led to a highly simplified representation, the number of state variables generated is still very large.

The 79 variables in each site are replicated 265 times to give a total of

\section{TABLE I}

Number of state and driving variables in the budworm/forest model

$\begin{array}{lr}\text { For each subregion } & 75 \\ \text { Density of host trees by age class } & 1 \\ \text { New foliage } & 1 \\ \text { Old foliage (retains memory of past stress) } & 1 \\ \text { Budworm } & 1 \\ \text { Weather } & 79 \\ \quad \text { Subregion total } \quad \text { (other variables included implicitly) } & \end{array}$


$79 \times 265=20,935$ state variables. Thus even this drastic simplification defines a system that is enormously complex for analysis. We discuss below a number of ways in which this complexity can be further reduced to promote understanding of budworm/forest interactions and the management problem. These further simplifications, backed by the laboratory world of the complete simulation model, are utterly essential to successful policy design. They are predicated on the existence of a critically bounded model which explicitly leaves out everything but the essential core of the problem.

All-inclusive models cannot promote the deep understanding of interrelationships necessary for creative policy design. Parsimony is the rule.

\section{CAUSAL RESOLUTION}

Myth: The goal of description is description.

If description per se were the goal of modeling, then there would be little need for a detailed understanding of causation. A multi-variate statistical model would be sufficient to capture and describe historically observed patterns of behavior. In fact, that is what was done in the original analysis of the budworm problem in New Brunswick, as reported in Morris (1963). The very best of sampling procedures were applied over a 15 -year period in a large number of locations, and a sophisticated statistical descriptive model was developed.

However, there are two problems. The first is that ecological systems often exhibit frequency behavior on the scale of decades or even centuries. As already shown in Fig. 2, the basic temporal pattern of the budworm system consists of periodicities of 30 and more years. It is hardly conceivable that there would ever be an extensive enough range of data to allow for a comprehensive description using statistical methods. At best, these can provide an effective way to mobilize whatever data are available and point to those processes or variables which contribute most to the observed variation. In addition, policies will be designed that move the system into regimes of behavior it has rarely if ever experienced during its evolutionary history. Considerable understanding of causation in terms of fundamental processes is required in order to be confident that the predicted behavior will be realistic under these novel conditions.

A certain degree of resolution in the hierarchy of causation is demanded; yet clearly one can go too far and become encumbered by details of explanation which defy comprehension. Modeling at too coarse or too fine a resolution level characteristically occurs when a system is not well understood.

This can often be avoided in the modeling of ecological systems. On the basis of a rich history of experimentation, theoretical analyses and empirical field studies, the structure of key ecological processes is known not only in some detail but within a framework which has generality. This understanding can be aggregated to produce general and well-tested modules of processes such 
as growth, reproduction, competition and predation.

The first step in developing an explicitly causal model is to identify the component processes involved. Figure 4 shows the detailed sequence of processes (and of calculations) which occur within each 1-year period in the budworm system.

The disaggregation cannot stop here. Each of the processes shown in Fig. 4 has to be represented in the model by functions as realistic but simple as possible. Two sets of decisions must be made - first, the mathematical form of the equation describing a particular process and, second, the parameter values for that equation. If no independent information is available to identify the form of the equation, an enormous demand is placed upon the available data which must be extensive enough to define both the equation and the parameter values simultaneously. In most instances, however, there is independent knowledge of process structure that allows the equation form to be determined. With the form defined, the available data need only define the parameters and the formerly impossible demands for data become tractable. This can best be demonstrated by a specific example.

One of the processes affecting survival of large larvae is predation by vertebrate predators (birds and squirrels). It has long been suspected (Morris,

PROCESS CYCLE

OF THE BUDWORM FOREST SYSTEM

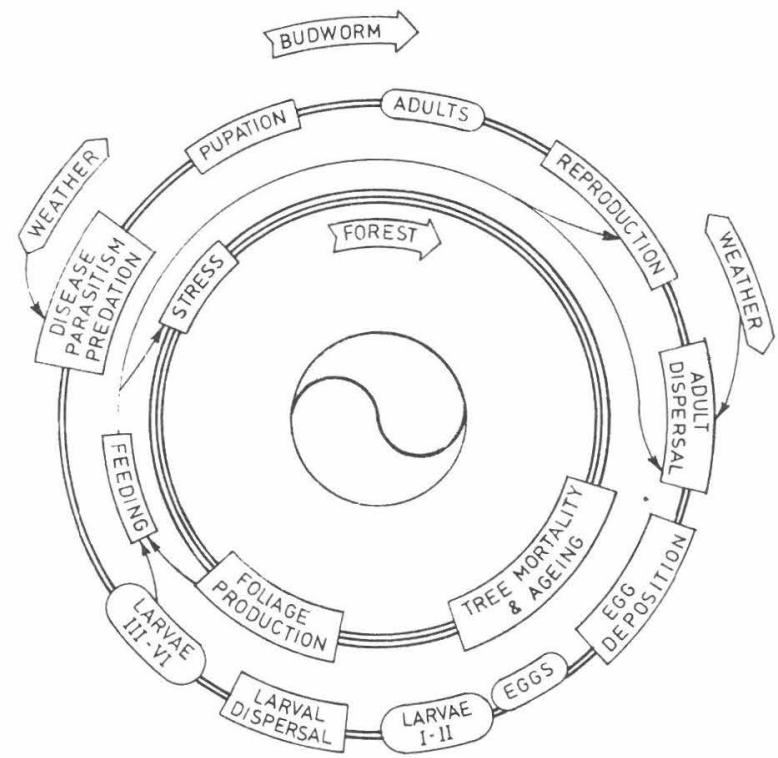

Fig. 4. The process cycle of the natural system. The inner ring represents the forest cycle, the outer ring, the budworm cycle. Ellipses indicate the insect life stages; arrows show causal relationships among processes and budworm densities. 
1963) that vertebrate predators could play an important role in the dynamics of spruce budworm when insect populations were low. For the very reason that it is so impractical to sample low populations with any reasonable precision and accuracy, standard regression modeling approaches have been wholly inadequate to capture the effects of predation.

The predation process, however, has been analyzed sufficiently so that its variety of forms can be identified and classified (Holling, 1965). Predation is comprised of four necessary and sufficient processes - the functional response to prey density (an instantaneous rate of attack), the competition response, the development response and the numerical response. Each of these four responses has been shown to have a small number of qualitatively distinctive forms (Holling and Buckingham, 1976). The functional response to prey density, for example, can assume four and only four qualitatively different shapes. Moreover, a simple general equation has been developed whose four limiting conditions generate all these types. Equally important, the sufficient biological conditions can be precisely defined so that the most general of information is sufficient to classify any specific situation.

We have analyzed existing data on vertebrate predation of budworm in some detail. For these sorts of predators, the functional response to prey density (i.e. the instantaneous number of prey eaten per predator per unit time) is known to rise in an $S$-shaped manner to a plateau. The appropriate form of the general predation equation is therefore established, and it remains only to mobilize the existing data so that feasible parameter ranges can be determined. For the present purpose, only two parameters need be defined - one that determines the plateau of maximum attack rate and one that determines the rate of search.

The parameter values are influenced by the size of the predator and its searching habits. This permits the separation of budworm predator species into distinct parameter-defined groups. The birds attacking budworm are classified into three types - the small arboreal birds (e.g. warblers), the medium sized birds searching nearer the ground (e.g., white-throated sparrows) and the larger birds with a variety of searching modes (e.g. grosbeaks). Existing data on maximum consumption, sizes of predators and rates of searching establish maximum and minimum feasible values for the search and satiation parameters for each class. Together, these define a feasible range for the percentage of late instar budworm larvae that can be eaten by birds (Fig. 5). Sensitivity analysis determined how changes in parameter values within this feasible range affected the qualitative behavior of the model. It was found that, as long as the predation mortality was within the range allowed by the data in Fig. 5, the typical outbreak cycle of 35 years was generated. If less predation was introduced, the model behavior reverted to a pattern of 8-12-year cycles which is characteristic of the model with no predation. (See Holling et al. (1979) for further details.)

In summary, a good rule of thumb is to disaggregate the model first into the constituent processes that together affect growth and survival. These 


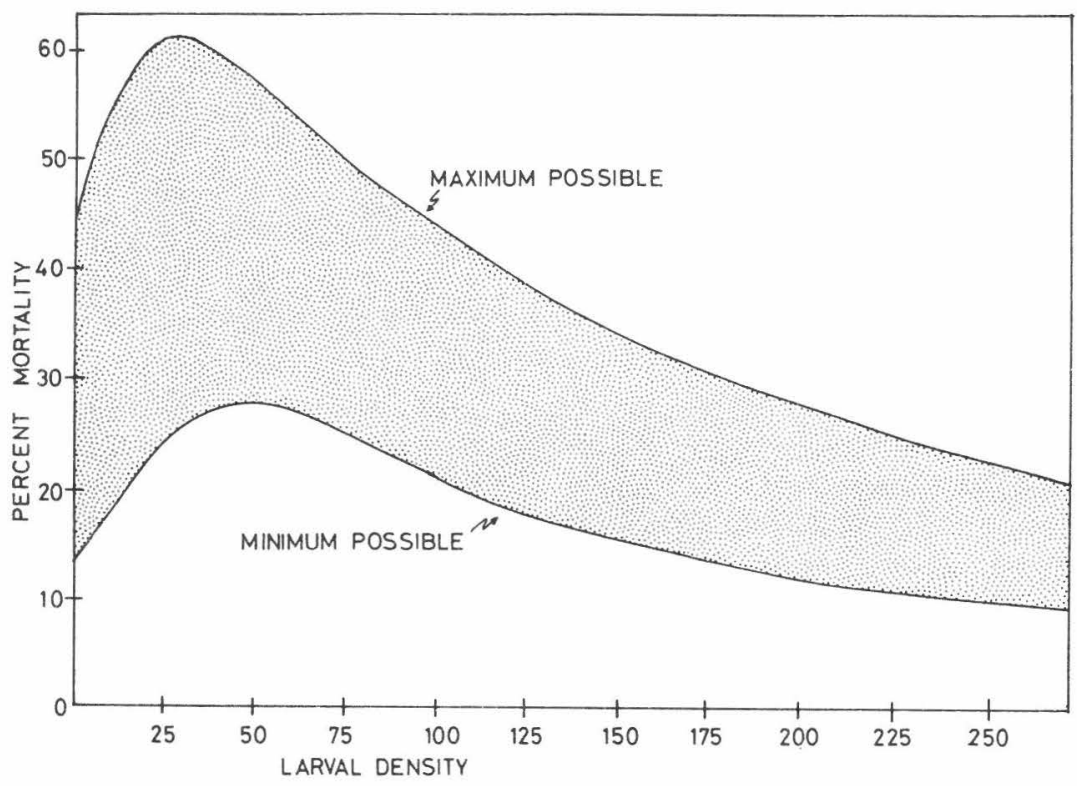

Fig. 5. Effect of vertebrate predators on budworm populations. Ordinate shows percent of sixth instar larval population consumed by predators as a function of larval density, given on the abscissa in units of thousands of larvae per hectare. Function shown is maximum, minimum, and range of predation rates consistent with available field data, all vertebrate predators combined (see text).

processes are then disaggregated one step further into their fundamental subprocesses. The principal purpose in choosing this level of causative resolution is to increase our confidence in predictions obtained under novel policies. Also, three additional benefits emerge which directly relate to our emphasis on transfer in dealing with the uncertain and unexpected. First, transfer implies that someone will be the recipient of the analysis. In many ecological problems these recipients include biologists and scientists with a sophisticated and highly detailed understanding of the mechanisms involved. Without disaggregating to the causal level suggested, the model is unlikely to be at all credible to these users. Moreover, there would be no way for the analysis to be responsive to the questions and critiques that, typically, are focused on distinct processes.

Secondly, modeling at this level of causation provides an effective way to identify factors that can be affected by policies. The qualitative behavior of the budworm/forest system is critically dependent upon vertebrate predation. Any policy which employs management acts (such as insecticides) which potentially could affect predators must therefore be evaluated in terms of possible changes in that process. It is not simply a matter of worrying about birds or other values, but rather of recognizing (in this case) the process of vertebrate predation as an integral part of potential forest manage- 
ment policies. A model that simply mimics past data would scarcely identify this as an issue.

Finally, some of the major advances in coping with the unexpected and unknown have applied the techniques of adaptive management (Walters and Hilborn, 1976). The key here is that, when our knowledge is tentative, management acts themselves can be designed to generate information relevant to an understanding of the underlying causal mechanisms. If our models have been conceptualized at a coarse level of resolution, the experiments of adaptive management can require extensive time or geographical areas to obtain results. This is impractical for management agencies with short time horizons and justified aversions to large scale trials. By disaggregating our models to the subprocess, or module level, "quick-and-dirty" experiments are often suggested which can yield results quickly in a localized and focused manner (Holling, 1976).

The goal of description is not description but useful causal understanding.

\section{INVALIDATION}

Myth: The purpose of validation is to establish whether the model is right.

There is always something about the real world which an abstract model will fail to predict, and there is always some model which can be constructed to mimic a given pattern of real world behavior. Proper validation is not a matching game, but rather an effort to explore the limits of model credibility. The establishment of these limits requires invalidation and not validation.

If our goal were to develop a micro-tactical model suitable for day-by-day predictions, then quantitative validation criteria would be in order. However, the present effort is aimed at a strategic level of regional planning, requiring projections over large spatial areas and long periods of time. Furthermore, the analysis is meant to evaluate new management situations without historical precedent. The best a quantitative validation comparison can do is assure us that we can model things that are already part of history. Confidence in the model's ability to treat new situations reliably will always be subjective to a degree. At a minimum, however, we can insist that the model generate plausible qualitative patterns of behavior in space and time under a wide range of extreme conditions. Behavior at the limits is more revealing than behavior under normal or average conditions.

Three kinds of qualitative information are available which relate to behavioral patterns of the budworm/forest system. The first concerns the "natural" or unmanaged system, and was referred to earlier when we discussed the bounding problem. The temporal pattern drawn from Blais' $(1965,1968)$ tree ring studies (shown in Fig. 2) suggests a natural inter-outbreak period of 30-45 years with occasional longer stretches and an outbreak duration of $3-6$ years locally and 7-16 years over large geographical regions. The natu- 


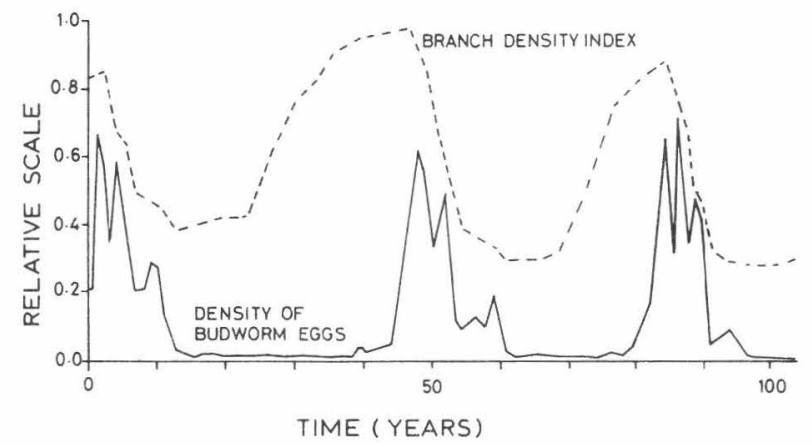

Fig. 6. Typical outbreak pattern generated by the model with no management or harvest ing imposed. Ordinate is a relative scale, running from 0 to 1000 budworm eggs per $10 \mathrm{ft}^{2}$ of branch area; and from 0 to 1 for the branch density index (see text) which closely parallels the average forest age and wood volume. Initial conditions are those for New Brunswick in 1953. Data are averaged over the 265 subregions. Compare with Figs. 2 and 7.

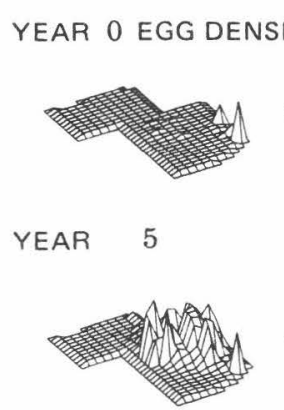

YEAR 10

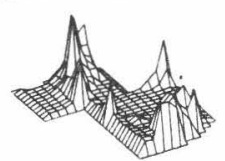

YEAR 15
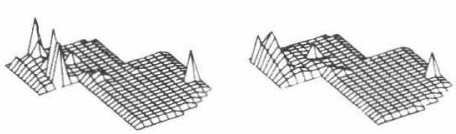

2

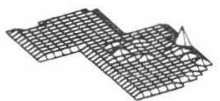

6

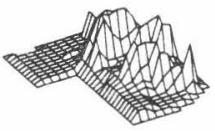

11

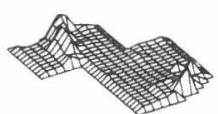

16

A

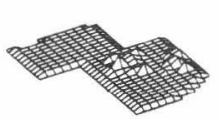

7

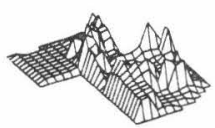

12

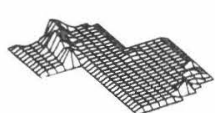

17

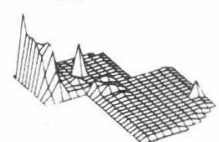

3

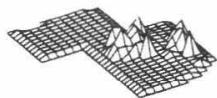

8

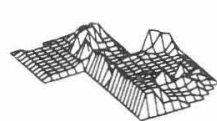

13

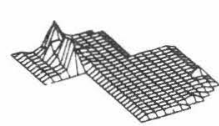

18

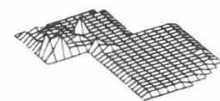

4

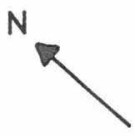

9

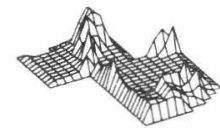

14

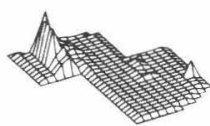

19

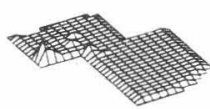


ral spatial pattern is reflected in extensive infestation records assembled by the Canadian Forest Insect and Disease Survey (Canada, Department of the Environment, 1938-1976), and reviewed by Greenbank (1957) and Brown (1970). In general, infestations move outwards in all directions from their areas of origin but expand most rapidly towards the east. Easterly spread rates for a new infestation may exceed $150 \mathrm{~km}$ per year in inland areas but are reduced to approximately $50 \mathrm{~km}$ per year near the Atlantic coast.

When the New Brunswick budworm forest model is run in the absence of management activities, the result is the temporal pattern of Fig. 6 and the spatial patterns of Fig. 7a and b. The temporal behavior of the model corre-

YEAR 0 EGG DENSITY 3

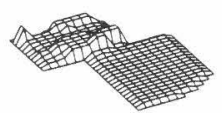

YEAR 15

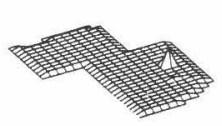

YEAR 48

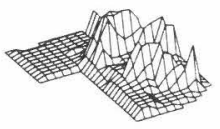

YEAR 63

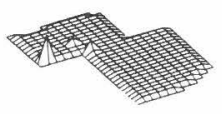

B
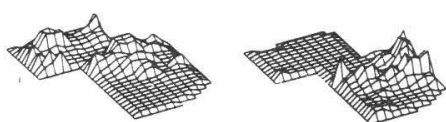

39

YEARS 16-38 NO CHANGE

51

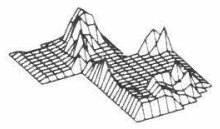

YEARS 64-77 NO CHANGE

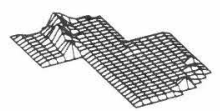

78

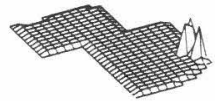

54

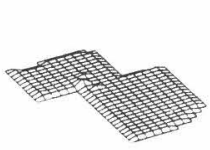

9

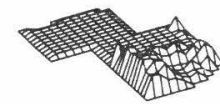

42

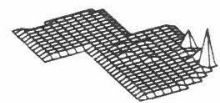

57

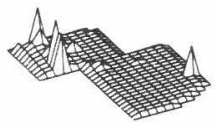

81

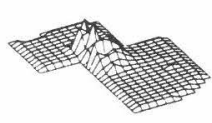

12
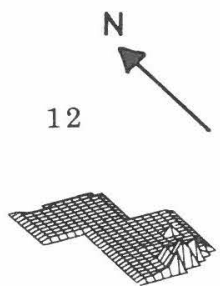

45

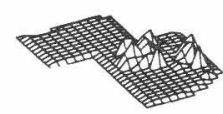

60

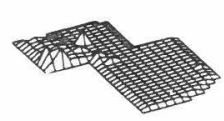

84

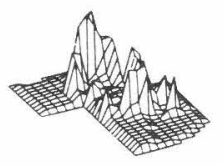

$$
\begin{aligned}
& 0 \quad 100200 \\
& \text { KILOMETERS }
\end{aligned}
$$

Fig. 7. Spatial outbreak pattern generated by the model with no management or harvesting imposed. Horizontal $(x, y)$ coordinates define east-west and north-south spatial grid of 265 subregions within the study area (Fig. 3). The vertical ( $z$ ) coordinate gives budworm egg density. (A) shows the year-by-year progression of a typical outbreak beginning in the southeast, spreading across the area, and dying out in the northwest 20 years later. (B) shows selected years from the model run for which averages were given in Fig. 6. Initial conditions are those of New Brunswick in 1953. 
sponds closely to the composite real-world picture of Fig. 2, generating 30-40 year inter outbreak periods and qualitatively similar levels of budworm density. The spatial pattern is also quite credible, even to the different rates of spread towards the northwest and southeast.

The second class of qualitative information concerns the behavior of the system under historical patterns of harvest and insecticide spraying. Egg density and defoliation patterns for New Brunswick between 1953 and the present are available from Webb et al. (1961) and data files of the Maritimes Forest Research Centre (C.A. Miller, personal communication, 1974). Harvest rates derived from Statistics Canada figures (averaging $4.25 \times 10^{6} \mathrm{~m}^{3}$ of wood per year) were applied to the model for this period. An average of $20 \%$ of the modeled region was "sprayed" with insecticide according to the historical, state-dependent spraying rules described by Miller and Ketella (1975). In these invalidation runs, all biological parameters have been determined by independent data (mostly from Morris, 1963) and remain fixed. The only "tuning" allowed is of the initial conditions (where they are ambiguous) and the management rules (harvesting trees and spraying insecticide) applied in the simulation model. The result is shown in Fig. 8. Initial conditions in year 0 are set as those observed in New Brunswick in 1953. Therefore, the first 23 years of this simulation run correspond to the period 1953-1975. Again, the agreement between real and simulated behavior is striking. Detailed numerical comparisons have been carried out, but in both cases the significant qualitative characteristic is a slowly eroding forest maintaining a persistent moderate level of infestation. The outbreak starts in the north, collapses there and throughout much of the province, re-emerges in the central regions and, in the early 1970's (year 21), spreads dramatically throughout the entire region (Canada, Department of the Environment, 1953-1976). The key point is that the spraying policies employed to keep the forest green, and so to preserve the forest industry, do so at the expence of maintaining semi-outbreak conditions markedly different from the "boom-and-bust" natural system (Blais, 1974).

The final and, in several ways, most powerful invalidation test makes use of the fact that temporal and spatial behavior of the budworm/forest system in New Brunswick is qualitatively different from behavior in certain other regions of North America. In northwestern Ontario, for example, outbreaks are more intense (Elliot, 1960) and tend to occur at intervals of 60 or more years rather than the typical 30-45-year period observed in New Brunswick (Blais, 1968). Another pattern has been observed in Newfoundland where budworm outbreaks used to be extremely rare (Canada, Department of the Environment, 1938-1965; I. Otvos, personal communication, 1975). Now, however, moderate infestations are a more common event, perhaps because of emigration from the mainland where a persistent and spreading outbreak has been maintained by insecticide spraying (Canada, Department of the Environment, 1966-1976). The principal differences between these two regions and New Brunswick are weather conditions and forest structure. In 

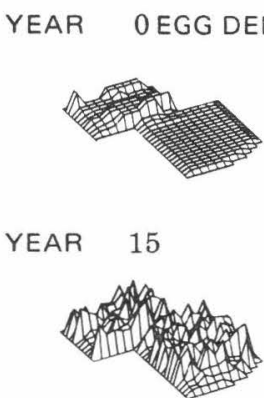

YEAR 30

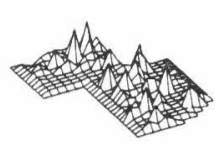

YEAR 45

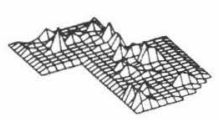

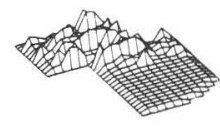

18

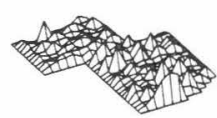

33

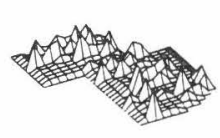

48

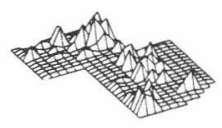

6

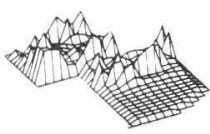

21

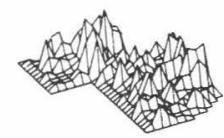

36

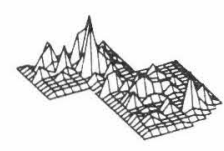

51

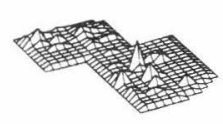

9

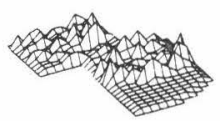

24

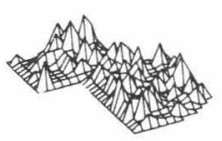

39

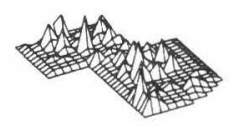

54

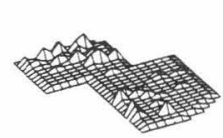

12
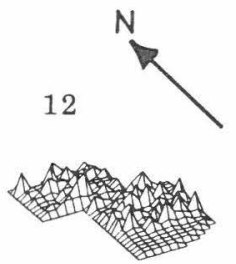

27

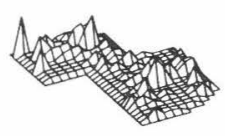

42

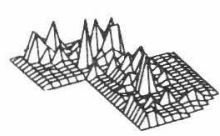

57

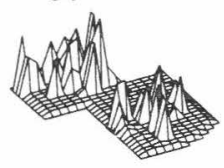

KILOMETERS

Fig. 8. Spatial outbreak pattern generated by the model under historical rules for spraying insecticide and harvesting trees. Initial conditions are those for New Brunswick in 1953. Compare with Fig. 7 (b), noting the loss of spatial cohesion of the outbreak due to management activities. The average time trace, analogous to Fig. 6, is given in Fig. 15 (a).

northwestern Ontario, the proportion of susceptible host trees is less than New Brunswick while in Newfoundland it is greater. Moreover, relative to New Brunswick, the weather in northwestern Ontario is more favorable to budworm and in Newfoundland less favorable. These simple changes were introduced into the New Brunswick model. Gratifyingly, the Ontario model scenario did generate more intense outbreaks at intervals of 60 rather than 30-40 years. Similarly, the Newfoundland changes produced a world free from outbreaks except under severe invasion by external dispersers exactly the phenomenon implicated in the recent Newfoundland infestations. These and other simple, qualitative, but highly significant tests are reported at length in Holling et al. (1975) and Clark and Holling (1979).

The three kinds of qualitative invalidation reviewed here place more rigor- 
ous demands upon the descriptive and predictive capability of the model than would any effort to fit a specific time series. By focusing on patterns in space and time, it is possible to mobilize qualitative information on a variety of behavioral modes associated with contrasting regional and historical management actions. The model's ability to reflect this broad spectrum of qualitative behavior establishes a significant degree of confidence in its utility for exploring policies which move the system far from its natural or historical conditions.

The goal for invalidation of a strategic model is to establish the limits of model credibility. A minimum requirement is agreement with a range of observed temporal and spatial patterns under a wide variety of extreme conditions. A quantitative fit to one set of data is quite insufficient.

\section{SIMPLIFICATION AND COMPRESSION}

Myth: A complex system must be described by a complex model.

Even the most ruthlessly parsimonious but realistic ecological simulation model will be encumbered by many state variables and nonlinear functional relations. The explosive increase in the number of variables required for spatially dispersed systems presents the "curse of dimensionality" in its more intractable form. Compressions and simplifications therefore are essential, in part to encapsulate understanding and help intuition play its central role in the analysis; in part to facilitate communication in the transfer process; and in part to exploit the potential of optimization techniques that are as yet unsuitable for nonlinear stochastic systems of high dimensionality.

A powerful approach is to adopt a topological view of the system. This links the basic qualitative behavior to the number and interrelation of equilibrium states and focuses as well on our central concern for ecological resilience and policy robustness. Our first step was to use the full simulation model to generate a population growth rate or "reproduction" curve similar to that introduced by Ricker (1954) for the analysis of fish populations. This has been done in Fig. 9, where the population growth rate $R$ (the ratio of budworm density in generation $t+1$ to the density in generation $t$ ) is plotted as a function of budworm density. The growth rate curves condense all the reproduction and survival functions within the model and produce a unique curve for each state of the forest.

Interpretation of the curves is straightforward and focuses on the location and properties of the equilibrium points which occur wherever the growth rate $R$ equals 1 . These equilibria may be stable or unstable depending upon the sign of the slope of the curve as it passes through the $R=1$ line. Briefly, if a slight increase in density from the equilibrium point results in further increases in the next generation (i.e. $R>1$ ), or if a slight decrease results in further decrease $(R<1)$, then the equilibrium is unstable (represented as an open circle in Fig. 9). In contrast, where a slight increase in density from the 


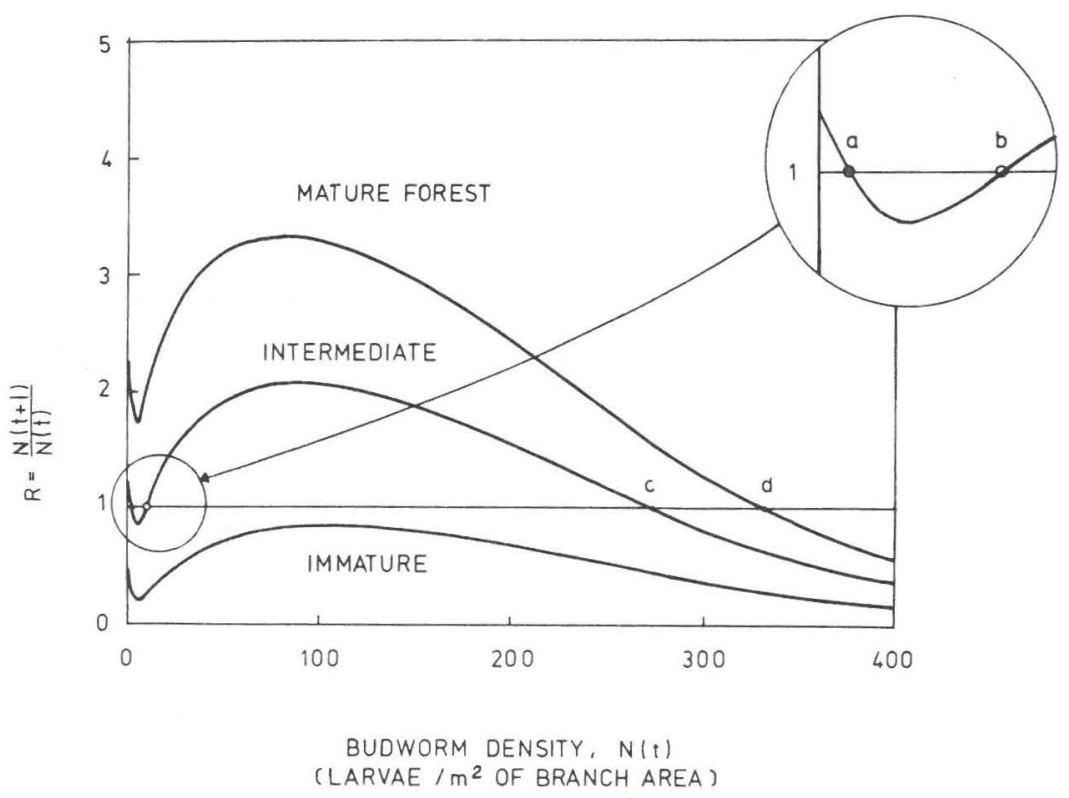

Fig. 9. Growth rate curves for budworm populations for three different forest conditions. Ordinate is population growth rate, defined as third instar budworm density in one year divided by density in the previous year. Abscissa is the previous year's third instar density. For any given forest condition, potential equilibrium budworm densities occur wherever the growth rate curve intersects the $R=1$ line. Equilibria can be either stable $(\bullet)$ or unstable $(O)$ (see text). Insert expands the intermediate forest curve at low budworm densities.

equilibrium point is offset by a decrease in the next generation $(R<1)$, and a slight decrease is offset by a subsequent increase $(R>1)$, then the equilibrium is stable (shown as a solid circle in Fig. 9 ). The interpretation of equilibrium properties for population growth rate functions is discussed at greater length in Takahashi (1964) and Holling (1973).

Subsequent discussion will draw heavily on interpretations drawn from these growth rate curves, so it will be useful to consider their structure in some detail. The high density equilibrium points (c, d in Fig. 9) are introduced largely through intraspecific competition among budworm for foliage. Although these points are stable equilibria for budworm, they are unstable for trees. At such high budworm densities defoliation is so heavy that older trees die and are replaced by seedlings and understory growth. This shifts the system onto a lower growth rate curve (e.g. the immature forest curve in Fig. 9) where $R<1$ and the insect population declines from its high level.

When the forest is immature, $R<1$ for all budworm densities and no outbreak is possible. With a very mature forest, however, budworm will increase from all densities less than $\mathrm{d}$. The ensuing defoliation and tree death will cycle the population back to low numbers. 
When the forest is of intermediate age, two low density equilibria are introduced, one stable (point a in Fig. 9) and one unstable (point b). The additional dip in the curves at low budworm densities reflects the activity of vertebrate predators as described earlier, and is augmented to a degree by parasitism. The population may persist at density a until improving forest conditions move the curve's dip above the $R=1$ line. An outbreak then occurs. An outbreak can occur even in an intermediate age forest if a sufficient influx of budworms disperses in from outside areas. Thus, in Fig. 9, a small influx of dispersers that increases the budworm density from equilibrium (a) to a density greater than the unstable equilibrium (b) (where $R>1$ ) will trigger an outbreak.

The growth rate curves shown here do not include the stochastic elements of weather which affect both survival and dispersal. When these are included, there is a third outbreak trigger in the occurrence of a sequence of warm, dry summers which can raise normally low growth rates above the replacement line.

A more complete and succinct summary of these multiple equilibria can be obtained by plotting all the equilibrium points as a three-dimensional surface in a space representing condensed forms of the three key state variables budworm, foliage condition and branch density (Fig. 10). This represents an

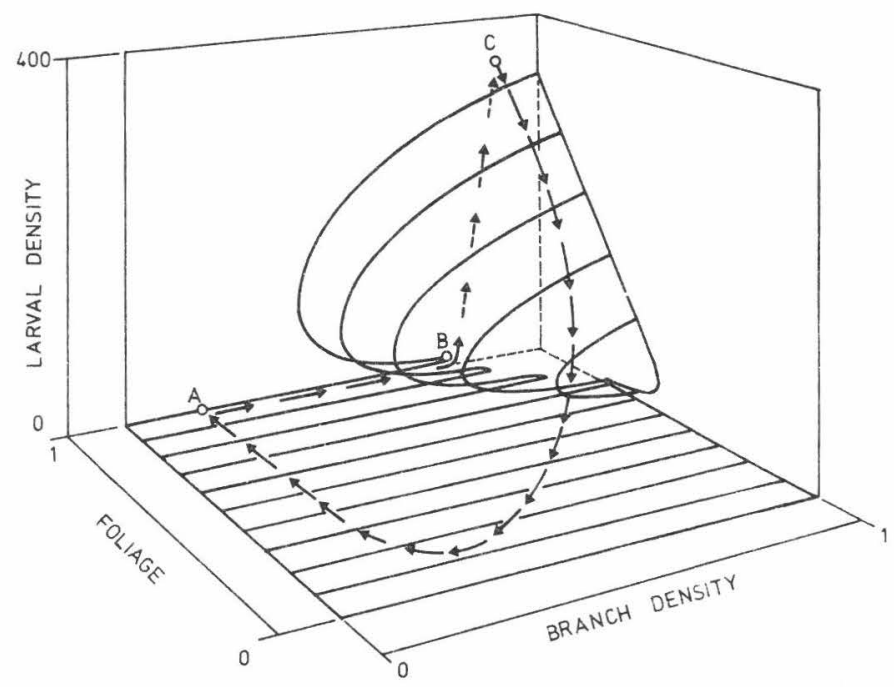

Fig. 10. Equilibrium manifold for budworm as a function of foliage and branch density (units are third instar larvae per $10 \mathrm{ft}^{2}$ of branch area, with foliage and branch density scaled 0 to 1 ; see text). Trajectory shows a typical unmanaged outbreak of the sort shown in Fig. 6. Segment AB is the long endemic period with budworm at low densities and the forest full of foliage and slowly growing until lower equilibrium disappears at B. Segment $\mathrm{BC}$ is the outbreak with budworm densities rapidly rising to upper equilibrium $\mathrm{C}$. At these densities, foliage is rapidly destroyed, leading to destruction of the forest and collapse of the outbreak along $\mathrm{CA}$, the final section sees the rapid recovery of foliage in a young forest, with budworm locked at their low density near A. 
equilibrium manifold of the kind found in topology and catastrophe theory (Thom, 1975; Jones, 1975). Such representations provide a particularly revealing way of interpreting outbreak behavior. The temporal pattern of the unmanaged system shown earlier in Figs. 2 and 6 can be understood by following the trajectory of events over this manifold as shown.

The equilibrium manifold representations also prove to be a powerful device for exploring the consequences of changes in ecological processes or management approaches. As one example, an equilibrium manifold is shown in Fig. 11 for which the foliage axis has been replaced by a predation intensity axis. When predation is at the level occurring in nature ( 1 on the scale), the pit responsible for the lower equilibrium is pronounced. As predation is relaxed, the pit gradually disappears along with the folded character of the manifold.

Under such conditions, the behavior of the system is radically and predictably altered, since the natural "boom-and-bust" pattern is intimately associated with the reflexive form of the manifold. Simulation runs conducted to check this topological implication of reduced predation show a world of perpetually immature forest where moderate budworm densities oscillate with foliage in a 12--16-year cycle. Since insecticides have exhibited a potential for reducing vertebrate predation directly through mortality or indirectly by affecting food availability (Pearce, 1975; Pearce et al., 1976), the significance of this result for management is obvious.

Another example is shown in Fig. 12, where the manifold is used to explore the qualitative implications of dispersal. The "immigration" axis reflects the relative intensity of immigrating budworm moths. The similarity

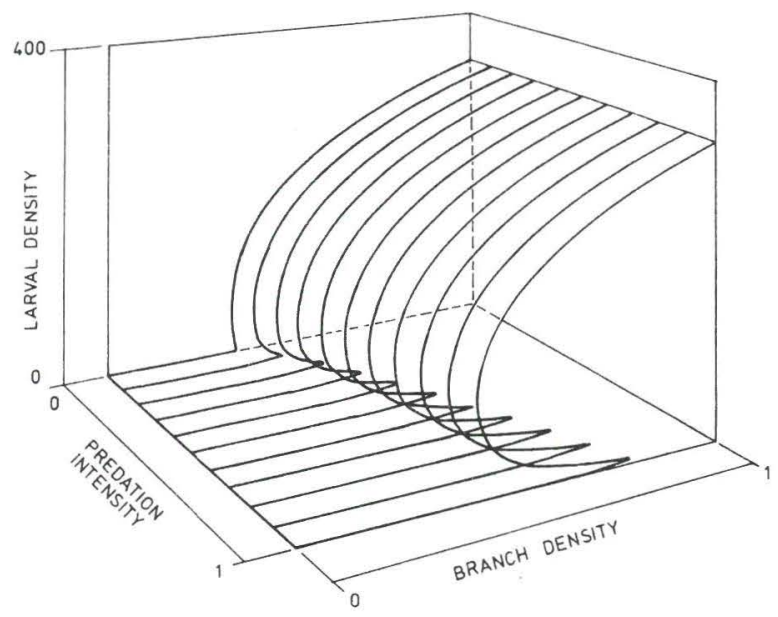

Fig. 11. Equilibrium manifold for budworm as a function of predation intensity and branch density. Predation scaled from 0 (no predation) to 1 (natural level of predation as included in model); other scales as in Fig. 10; foliage is set at 1. 


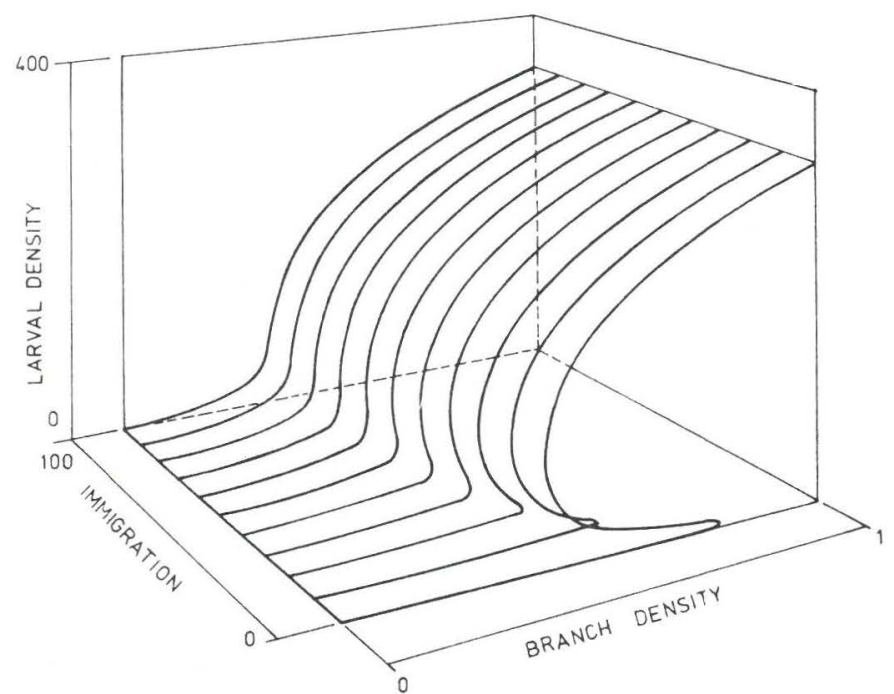

Fig. 12. Equilibrium manifold for budworm as a function of budworm immigration rate and branch density. Immigration scale from 0 (no immigration) to 1 (an arbitrary but feasible rate; see text). Other scales as in Fig. 10; compare with Fig. 11.

of the dispersal manifold to that for predation is striking and significant. An increased rate of immigration clearly has qualitative properties much like those of a decreased rate of predation. This is in keeping with the earlier analysis of growth rate curves in Fig. 9, where the quantity of immigrants necessary to release a budworm population from its low density equilibrium was obviously related to the "size" of the predator-induced pit. As would be expected from the comparison of manifolds, a systematic increase in immigration affects the model very much like a systematic decrease in predation, flipping the budworm/forest system into its alternative behavioral mode of a sustained outbreak exhibiting a 12-16-year insect-foliage cycle.

The greatest payoff from the topological simplifications comes in their implications for policy. In discussing the growth rate curves of Fig. 9, we noted that a forest could be so immature that no outbreak was possible under any conditions (i.e. $R<1$ for all budworm densities), or so mature that an outbreak would ensue if any budworm at all were present $(R>1$ for all but extreme budworm densities). This phenomenon is reflected more clearly on the budworm-foliage-branch density manifold originally presented in Fig. 10 and redrawn in Fig. 13. The manifold has been raised above the foliage-branch density plane to illustrate critical regions of forest condition that influence budworm behavior.

Recall that an "outbreak" consists of the budworm population moving from the lower to the upper manifold surface. This is impossible if the forest is in the "inter-outbreak" region (I) of Fig. 13, since for these forest conditions no upper equilibrium surface exists. Any policy which keeps the forest in region (I) will be immune to budworm outbreak. Unfortunately, and 


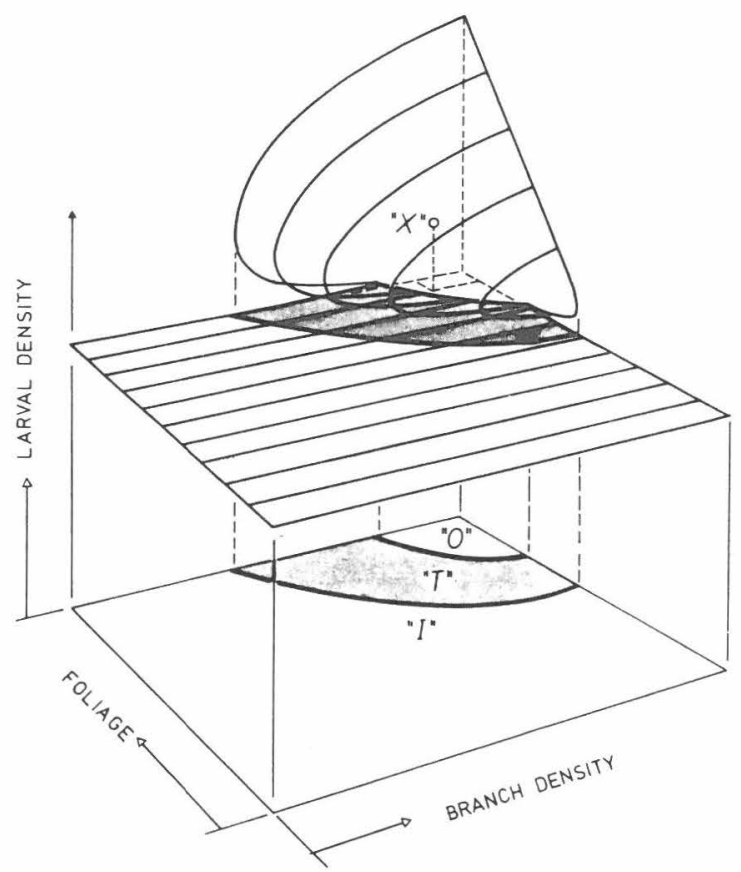

Fig. 13. Equilibrium manifold for budworm as used in policy analysis. See text.

hardly by coincidence, it will also be an unprofitably young forest, a defoliated forest, or both.

In contrast, a mature an'd green forest in the "outbreak" region $(\mathrm{O})$ of Fig. 13 is guaranteed to produce an outbreak. Only the upper equilibrium surface exists, and any (non-zero) budworm density will increase until this surface is reached. The only management act of much significance while the forest remains in this condition is one which imposes extrinsic mortality on the budworm, keeping it from reaching its equilibrium surface where it would defoliate and kill the trees. Region $(\mathrm{O})$ represents precisely the situation reached in New Brunswick in the early 1950's: the full-foliage forest matured and the inevitable outbreak began. Intensive insecticide spraying was introduced to protect the forest by killing budworm. The outbreak was indeed retarded, and the system was held near state (X) in Fig. 13 - a state with moderate levels of budworm, fairly dense foliage and a mature forest.

Note, however, that point (X) does not lie on any equilibrium surface; it is manifestly an unstable and "unnatural" configuration for the system, entirely dependent on the continued external application of severe budworm mortality through insecticides. The maintenance of this state is extremely sensitive to any policy failure which decreases this mortality - be it through evolved genetic resistance, errors in spray formulation and delivery, or legal restrictions on spray dosages, targets and frequency. New Brunswick has 
recently discovered this in a most disagreeable way (Miller and Ketella, 1975; Baskerville, 1976).

The intermediate forest "threat" region (T) is the only one for which the outbreak issue is in doubt. Budworm densities below the reflex fold of the equilibrium surface are attracted to the lower, or endemic, surface. Densities above the fold are attracted to the upper, or outbreak surface. The availability of the lower surface immediately suggests that insecticide policies designed to "knock out" the budworm deserve consideration. On the other hand, we have already shown how dispersal and predation can affect the configuration of the fold and consequently expand or contract the range of forest conditions included in region $(\mathrm{T})$. The success of any policy seeking to maintain the forest system on the lower surface of region ( $\mathrm{T})$ will therefore be critically sensitive to various unknowns, both those that impinge on the descriptive model which produced the manifold configuration, and those that unexpectedly change immigration or vertebrate predation intensities in the real world. These critical relationships are due particular attention in the succeeding policy design and evaluation process.

In summary, simplified and compressed versions of the simulation model - the laboratory world - can be captured in topological manifolds which focus upon the multiple equilibrium properties of that model. The manifolds can be calculated directly from the simulation model, as above, or generated from simplified, qualitative equations of the system's structure (Ludwig et al., 1978). In either case, the manifolds can then be exploited to improve understanding of system behavior and structure, and to qualitatively diagnose regions of policy sensitivity and potential. How this qualitative understanding can be put to direct use in the design and evaluation of detailed management policies will be shown in the next two sections.

Clearly, if the descriptive part of the analysis stops at the development of a complex simulation model, the clarity of understanding needed for transfer and policy design is seriously compromised. Again, creative simplification is necessary for understanding.

\section{THE DEVELOPMENT OF POLICY ALTERNATIVES}

Myth: The goal of policy design is the design of optimal policy.

The first responsibility of policy design is to generate and explore a strategic range of alternative approaches to the management problem. Subsequent efforts can seek to evolve a satisfactory or, more ambitiously, an optimal policy from this initial range. Unless the analysis insists from the outset on explicitly enriching the decision environment, then the policy design process will consist of little more than an unguided sequence of incremental modifications to the status quo (Braybrooke and Lindblom, 1963). Such cautious incrementalism is an appropriate procedure for a globally stable system but, as we argued earlier, it is a particularly dangerous way to manage in 
a world of multiple equilibria and uncertainty.

Prescription is an iterative process of specifying objectives, articulating policy and evaluating performance. We elect to enter this cycle by identifying a strategic range of alternative objectives as departure points for the analysis. The goal is not to define complex realistic objectives but to pose a strategic range of simple alternatives which encompasses the specific goals which may be sought by particular groups of individuals.

At one extreme of the range lies the classical objective of unconstrained "optimal efficiency" - for instance, maximization of present value of the forest. At the other extreme, and equally simplistic, are the objectives of the maintenance of natural dynamic variability. Table II lists eight of the principal alternatives used as points of departure in our budworm policy design studies.

Given a point on this strategic range of objectives, the next problem is to identify policies (i.e. sets of management rules) which will effectively promote those goals. We could, of course, seek to identify appropriate policies by simple heuristic gaming with the simulation model, but except in the most trivially simple cases, this would be a prohibitively slow, expensive, and inefficient way to develop interesting (much less optimal) policies. The number of possible policy formulations is generally so large that some formal guidance is necessary to define interesting regions in policy space. We need an organizing "brain" for the idiot simulation (Watt, 1963; Holling and Dantzig, 1977).

A variety of mathematical programming and optimization techniques have been developed to provide such guidance, but they are not yet up to the task presented by even simple ecological management problems. The high dimensionality of ecological systems cripples dynamic programming, while the

\section{TABLE II}

Examples of alternative objectives explored in the budworm policy analysis

(1) Retain existing management approaches ("historical management")

(2) Eliminate all human intervention, both harvest and budworm control, to recreate a natural system

(3) Minimize budworm densities

(4) Minimize budworm densities while eliminating insecticide applications (e.g. replacing with methods of biological control and/or forest management)

(5) Maximize long-term profits to logging industry

(6) Maximize long-term profits to logging industry without exceeding present industrial capacity or operational constraints, and without violating environmental standards regarding insecticide application ("constrained profit maximization")

(7) Maximize long-term profits to logging industry subject to constraints of (5), simultaneously maximizing recreational potential of forest

(8) Transform the system's existing temporal variability into spatial variability (i.e. develop a forest in which the budworm functions as a forest manager and the essential dynamic interplay of natural forces is retained) 
essential nonlinearities and stochasticities militate against such relatively dimension-insensitive techniques as linear programming and its variants. Drastic simplification of the descriptive model is necessary to obtain any of the benefits of mathematical programming; yet with that simplification, all guarantees of real-world optimality for the resulting policies are inevitably lost.

Our response to this dilemma has been to employ first a variety of formal, and then several heuristic optimization techniques in an iterative "probing" of policy space. Extensive work has been carried out using various forms of dynamic programming (Winkler, 1975), "fixed-form" parameter search techniques (Walters and Hilborn, 1979; Stedinger, 1977), graphical nomogram approaches (Peterman, 1975, 1977b), and a combination of intuition and analysis relying heavily on the manifolds discussed previously. Rather than try to review all of this work here (see Yorque et al. (1978)), we will focus on the results obtained and lessons learned through just one sequence of optimization techniques applied to just one of the alternative objectives. objectives.

Winkler and Dantzig (Winkler, 1975; Holling and Dantzig, 1977) used dynamic programming to calculate the conditions of tree age, foliage and budworm infestation for which insecticide spraying or tree harvesting are prescribed. The dimensionality problem was resolved by viewing the forest as a collection of single trees. Movement of budworm between trees was simplified by assuming that the number leaving a tree would be balanced by the number arriving from other trees. The analysis resulted in a set of management rules ostensibly "optimal" for the (extreme) objective of maximizing long-term logging profits. These rules take the form of policy "look-up" tables telling the manager what to do each year for any possible condition of his forest (Figure 14).

It was essential to test the Winkler-Dantzig policy in the complete regional simulation model to determine whether, in spite of the simplifications necessary to perform the optimization, it still provided an interesting starting point for further investigation. The results of this test were dramatic, as can be seen in a comparison of Fig. $15 \mathrm{a}$ and b. In contrast to the historical management simulation, the budworm outbreak is rapidly smothered and thereafter prohibited by the Winkler-Dantzig policy and very little budworm-induced tree mortality occurs.

These results suggest that formal optimization procedures applied to simplified models can yield starting points for policy design that are as good as or better than those developed historically. These can then provide focus for a dialogue with managers, scientists and policy people to identify modifications for subsequent heuristic exploration.

For example, there are unique management constraints in any specific region. In New Brunswick, the industrial capacity limits the annual tree harvest, insecticide spraying is only practical in large blocks, and environmental and health regulations limit insecticide dosages. Some, but not all, of these constraints could be incorporated into formal optimization but this would 

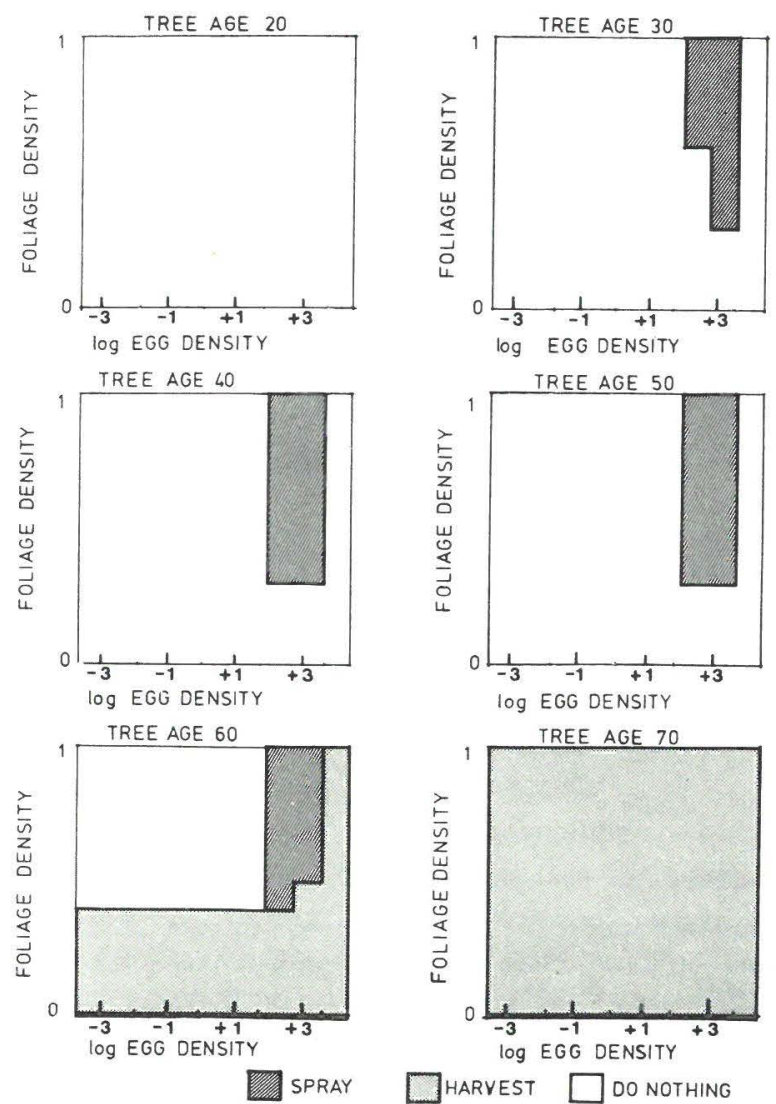

Fig. 14. Representative policy tables generated by the Winkler-Dantzig optimization. A separate table is provided for each age of tree (or, in practice, each mean age of stand). The table tells which management act (spray, harvest or do nothing) should "optimally" be applied as a function of field measures of trees present, foliage density (scaled as previously), and egg density (eggs per $10 \mathrm{ft}^{2}$ of branch area, here on a common logarithmic scale).

limit its value for other regions which have different constraints. Therefore, additional constraints are included, and the policies adapted heuristically in collaboration with the managers and policy people who have specific knowledge of the system. When the constraints mentioned above were included, the behavior shown in Fig. $15 \mathrm{c}$ was generated. Clearly, the original "optimal" policy is sufficiently robust to operate reasonably well even within the more realistic operational setting of New Brunswick.

Heuristic modifications of an initial policy probe can go far beyond such tests of practicality. Totally novel rules and actions can be identified but again, dialogue is essential, and dialogue is only useful if information is generated that is directly relevant to the people affected. State variables have 
(a) HISTORICAL MANAGEMENT

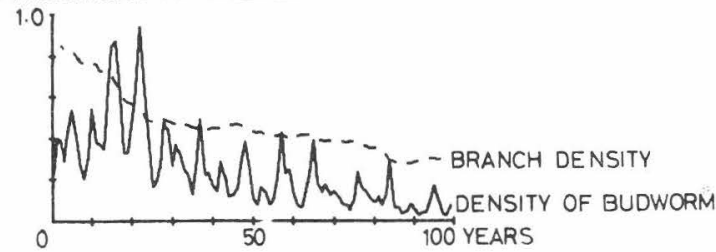

(b) UNCONSTRAINED WINKLER-DANTZIG MANAGEMENT

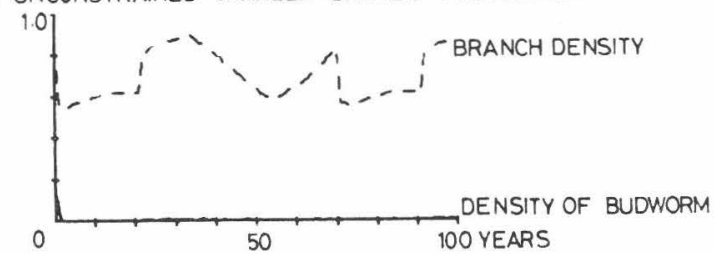

(c) CONSTRANED WINKLER-DANTZIG MANAGEMENT

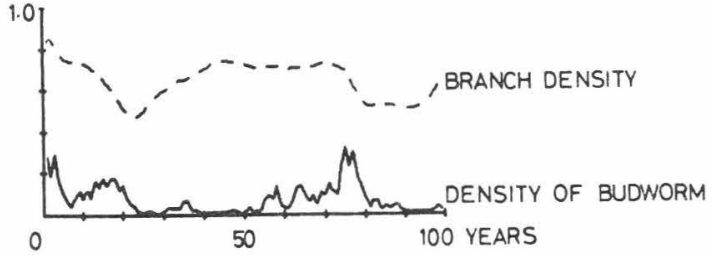

Fig. 15. Behavior of the budworm simulation under three management programs. Labeling conventions and initial conditions as in Fig. 6. "Historical management" rules are those used in New Brunswick in the 1960's and 1970's (spatial results for these rules are given in Fig. 8). "Unconstrained Winkler-Dantzig management" employs the rules shown in Fig. 14. "Constrained Winkler-Dantzig" rules introduce realistic constraints on total industrial harvest capacity and permissible rates of insecticide application.

meaning for the analyst. But social, economic and environmental indicators have meaning for the practical policy maker. To go further in the iterative process of policy design, it is necessary to generate and evaluate indicators of policy performance. That is the focus of the next section, so that we will reserve further examples of heuristic policy development for discussion there.

We conclude that formal and simplified optimization can provide a number of useful starting points for a process of policy design and dialogue. In no sense does it guarantee an optimal or even adequate policy.

\section{THE EVALUATION OF POLICY PERFORMANCE}

Myth: The goal of the evaluation process is to choose the policy best reflecting the decision makers' preferences.

Choice implies a given set of policies, one of which must be selected as "best" with respect to a given objective. The evaluation process properly 
includes such questions of choice but, as elsewhere, the essential goal is to promote understanding - in this case through meaningful characterization of the managed system's performance under alternative policies.

Socially relevant and responsible evaluations cannot be based upon the system's state variables we have used to this point. Rather, they require a broader set of indicators relevant to those who make, and those who endure, the ultimate policy decisions. Two classes of indicators are required, one focusing on broad questions of policy resilience and robustness, the other upon more immediate concerns of management and planning.

Resilience indicators for evaluation are a critical but as yet only partially developed aspect of the science of ecological policy design. We have explored the concept and discussed its implications and difficulties elsewhere (Holling and Clark, 1975; Holling, 1978). It would be premature to accord any of this experience the status of "lessons for policy design", and we will not dwell on it here. The important point is that resilience indicators are essentially measures of topological sensitivity. They focus upon the implications for policy performance of qualitative changes in configuration of the equilibrium manifolds governing system behavior, and not on the traditional quantitative measures of parametric and state variable sensitivity. The resulting indicator metrics are crude, but begin to provide a meaningful framework for dealing with the unexpected and unknown in policy design (Yorque et al., 1978).

The more traditional indicators of management performance are comparatively easy to generate, and can often be partitioned into categories of the sort shown in Table III. The detailed structure of these indicators need not concern us here (see Bell (1977b) and Yorque et al. (1978)). Suffice it to note that they were defined by the New Brunswick scientists, managers and policy makers as relevant to their evaluation of alternative policies. Specific indicator values are generated by the simulation, just as it generates values for the biological variables discussed earlier.

At an early stage in the evaluation, each decision maker can choose the particular indicators which interest him and examine the simulated time behavior of each under alternative policies. There are rigorous techniques for comparing policies through the patterns of their indicator behavior, and we will touch on these below. Sometimes visual inspection of indicator patterns is sufficient to show that one policy completely dominates another. More commonly, some of the policy trials are likely to exhibit obviously desirable behavior in others. Traditional evaluation procedures seek to provide a common denominator for ranking such complex alternatives. But we have found the opposite approach to be constructive - viewing evaluations initially as a means of highlighting differences in policy performance. These differences are then used by the policy design process to develop new management alternatives.

For example, even though indicator performance of the constrained Winkler-Dantzig policy (Fig. 17) is superior to that of the historical rules (Fig. 16), it still uses insecticides persistently and extensively. These chemi- 
TABLE III

Examples of evaluation indicators generated by the model

Socioeconomic indicators

(1) Total costs to the logging industry (not including insecticide)

(2) Total costs as a proportion of total sales

(3) Cost per unit volume of harvested wood

(4) Cost of insecticide spraying

(5) Employment rate reflecting proportion of mill capacity utilized

Resource indicators

(1) Volume of wood in trees older than 20 years

(2) Volume of wood in trees older than 50 years

(3) Volume of wood harvested

(4) Proportion of total volume harvested

(5) Volume of wood killed by budworm

(6) Mill capacity

Environmental indicators

(1) Damage due to visible defoliation

(2) Logging damage

(3) Age class diversity of the forest

(4) Recreational potential of affected sites

(5) Insecticide impact in terms of fraction of province sprayed

cal insecticides, however useful as armaments of the forest manager, are an environmental poison that inevitably affects many species other than the target organism. The overall consequences of their pervasive use will always be risky and uncertain, and reduction of our reliance on them is obviously desirable. We now show one example of how the initial Winkler-Dantzig probe can be heuristically modified to reduce insecticide use without compromising the desirable aspects of indicator performance. Our tools are the equilibrium manifolds (Figs. 10-13) described in the earlier section on compression and simplification.

Recall that budworm populations remain at endemic levels as long as they are within the "pit", on the lower stable surface of the manifold. When forest growth carries the system beyond the end of the pit, the lower surface vanishes leaving only the upper attracting surface and an outbreak is triggered. This manifold interpretation immediately suggests that one way to minimize outbreaks, and hence the use of insecticides, is to manage the forest through harvesting so that it never achieves sufficient maturity to exit the pit (i.e. to move into region " $O$ " in Fig. 13).

Under conditions of average weather and full foliage, the end of the pit, and the loss of the lower equilibrium, is reached when the branch density index is about 0.75 . Thus a new policy was designed making one addition to the constrained Winkler-Dantzig rules. If after spraying and harvesting 

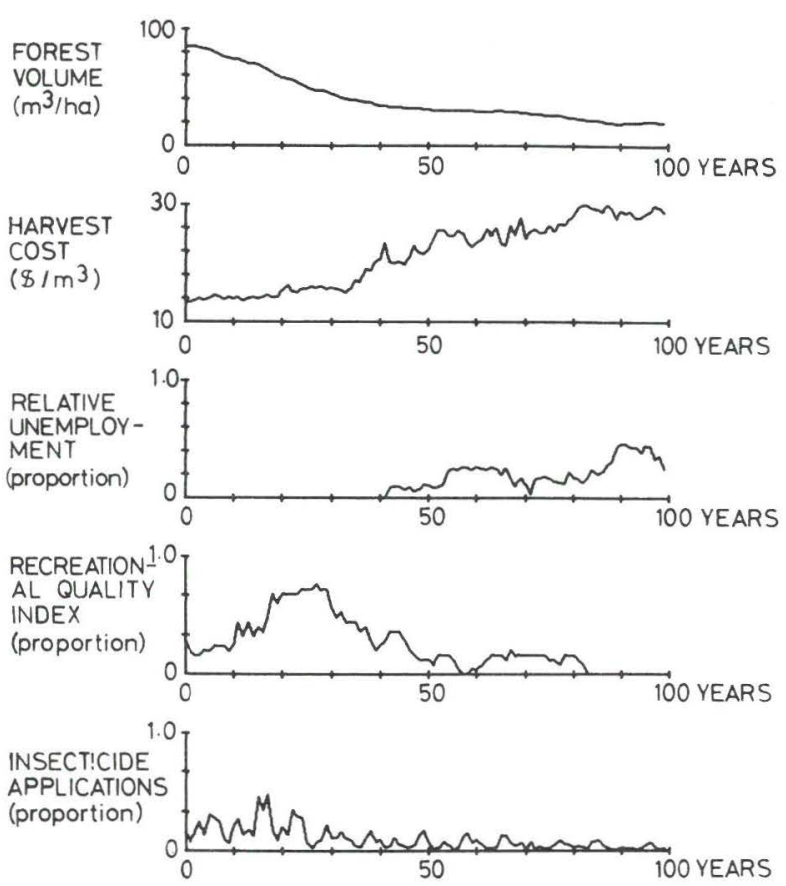

Fig. 16. Policy evaluation indicators under "historical management" rules (compare Fig. 15 (a). Graphs show the undiscounted value of the indicators in each year. Forest volume is a density in cubic meters of merchantable timber per hectare of fully stocked forest, including only species susceptible to budworm. Harvest cost is for timber delivered to the mills, and is expressed in 1972 Canadian dollars per cubic meter of wood. It includes all stumpage, cutting, and transport costs. Unemployment is a relative rate, calculated as the proportion of mill capacity unutilized due to unavailability of suitable timber. Mill capacities are taken from historical data (1953-1975) for the first 23 years of each simulation, and fixed at 1975 values thereafter. Recreational quality reflects a complex function of logging and budworm damage, access, and forest age structure. Twenty-five subregions with high recreation potential are monitored with respect to these characteristics, and the proportion exceeding a predefined recreational quality rating in each year are recorded. Insecticide applications indicates the proportion of the study area sprayed each year.

according to Winkler-Dantzig policy, the forest's branch density remained above 0.75 , a quantity of older trees were harvested so as to bring this value down to 0.75 . This hybrid "branch density" policy was evaluated in the full regional model and the resulting indicator traces are shown in Fig. 18.

The objective to minimize spraying is achieved with the hybrid policy. The average area sprayed, once the initial outbreak is brought under control, drops from $25 \%$ in the original constrained Winkler-Dantzig policy (Fig. $17)$, to $2 \%$ when the "branch density" rule is added. Unhappily, the behavior of some other indicators has deteriorated. Total forest volume is brought to a lower value and, more important, unemployment is erratic and generally 

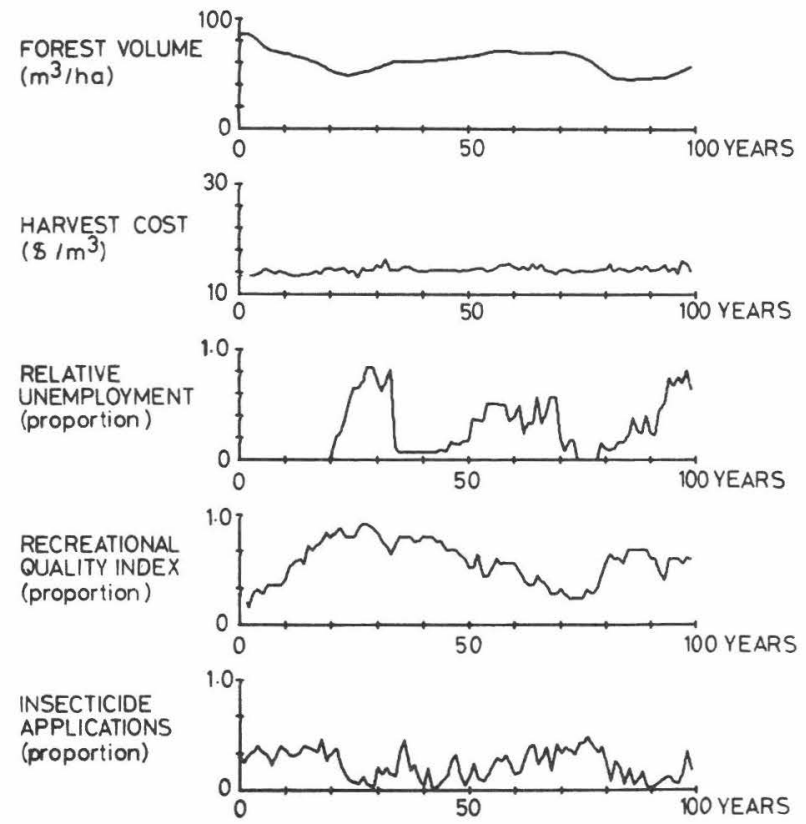

Fig. 17. Policy evaluation indicators under "constrained Winkler-Dantzig management" rules (compare Fig. 15 (c). Indicators defined as in Fig. 16.
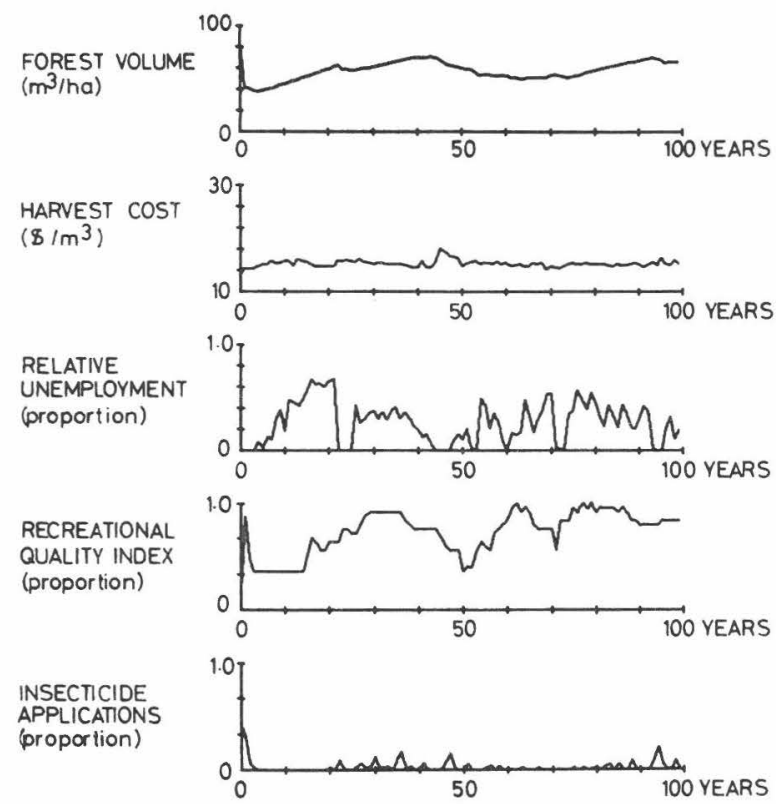

Fig. 18. Policy evaluation indicators under "branch density hybrid management" rules. Indicators defined as in Fig. 16. 
high. This is to be expected since initial overharvesting is required to bring the branch density to 0.75 which limits the supply in later periods.

The manifolds suggest several additional possibilities for improving the indicator traces, however. Rather than harvesting the forest down to the end of the pit, actions are possible which enhance the pit itself. For example, there exist a number of viruses which are highly host specific and thus potentially less damaging to the environment than insecticides. These agents have usually been treated as laboratory curiosities because they inflict only modest mortality on budworm. The manifold can be used to suggest new strategies for implementing these low mortality agents that significantly alter the dynamics of the budworm system.

The threat state (region "T" in Fig. 13) is defined as having low budworm densities (number of larvae less than 22 per $10 \mathrm{ft}^{2}$ of branch area) and intermediate branch densities (between 0.38 and 0.75). A forest in the threat state cannot spontaneously outbreak; it is held at the lower equilibrium until it is flooded by immigrants or until the forest matures beyond the end of the "pit". An additional mortality of only $25 \%$ applied to late instar larvae moves the end of the pit to a branch density value of 1.0. That is, the forest conditions need to be that much "better" to compensate for this additional mortality before a budworm outbreak begins. By applying this new control only at low densities and only in stands with branch densities nearing 0.75 we expand the threat state to a level of 1.0. The control would not be perfect as immigrants from other areas could still trigger an outbreak. Applying this mortality only at low budworm densities leaves the upper surface of the manifold unaltered.

This "pit enhancement" policy explicitly alters the shape of the manifold. However, the manifold is only a simplification of the complete model as we have not incorporated such things as stochastic weather and inter-site dispersal. Again a simulation run was generated on the complete regional model to test this new policy. The constrained Winkler-Dantzig rules were again used in conjunction with the additional provision that whenever those rules left a management area in the threat state as defined above, the pit was augmented by an additional $25 \%$ mortality, operative only under threat conditions. (This latter requirement is essential so as not to change the other equilibrium conditions which determine other kinds of qualitative behavior.) This new management act can be envisioned as the addition of a non-persistent and host-specific virus whenever the forest reaches the state defined or, alternatively, as the enhancement of vertebrate predator populations.

The resulting indicator traces are shown in Fig. 19. Suddenly our larger objective is achieved. Once the initial outbreak is brought under control by Winkler-Dantzig insecticide spraying, the need for further spraying is almost eliminated by the threat-triggered pit enhancement. Moreover, all other indicators behave as well or better than those of the original constrained Winkler-Dantzig policy rules (compare Fig. 17).

This same procedure has been applied for a variety of objectives from the 

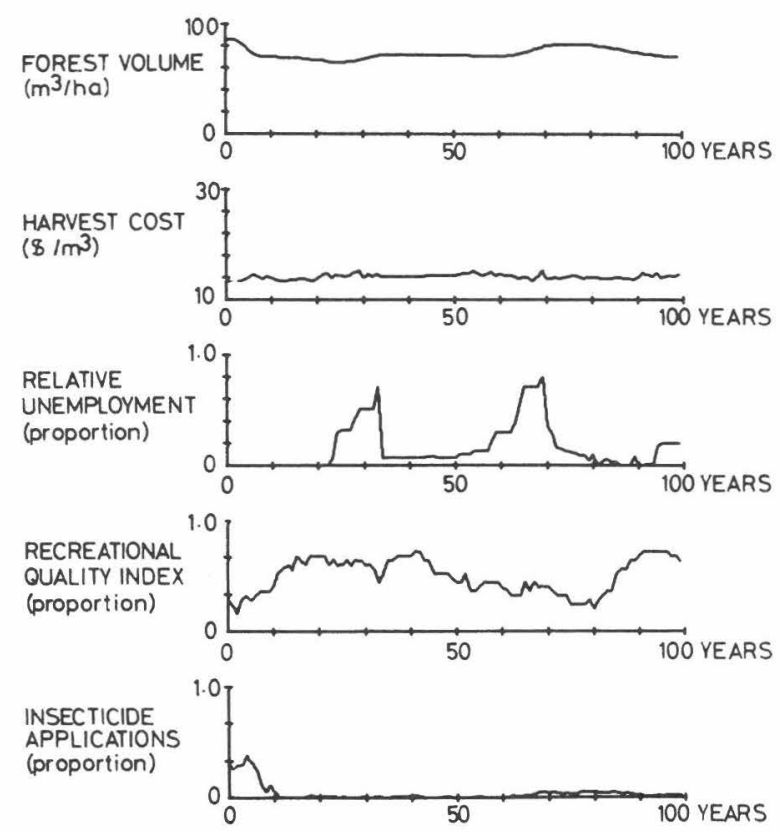

Fig. 19. Policy evaluation indicators under "pit enhancement hybrid management" rules. Indicators defined as in Fig. 16.

strategic range (Yorque et al., 1978). In all cases, an interesting trial policy was defined by an optimization procedure and then modified with the understanding provided by the topological analysis - each modification being evaluated using a comprehensive array of performance indicators. The procedure is a partly formal, partly heuristic process identifying new actions and rules which would otherwise elude consideration.

The evaluation of the examples discussed so far has been relatively straightforward - nearly all comparisons have offered a clear case of dominance by one indicator set over another. But the more extensive the array of indicators and the greater the number of policies to be compared, the greater is the danger of losing meaning in a wealth of numerical detail. For complex evaluation problems, some systematic approach to indicator compression is necessary. A number of concepts and techniques for multi-attribute problems are available from the field of decision analysis (e.g. Keeney and Raiffa, 1976) and several of the more practical have been brought to bear in this case study.

Preference evaluation interviews were conducted with representatives of management and research agencies, the forest industry, various provincial ministries, and the informed public. Participants identified their objectives for the forest system by specifying a set of relevant indicators and the desired levels of performance for each. In most cases, trade-off rates and 


\section{TABLE IV}

Utility evaluations of policy alternatives. Utility functions were evaluated over the sets of indicators shown in Figs. 16-19 for four decision makers in New Brunswick. Decision maker 'A' was a senior civil servant responsible for evaluating the benefits of policies to the province as a whole; ' $\mathrm{B}$ ' was an official in the environmental protection department; ' $\mathrm{C}$ ' was an academic consultant; ' $\mathrm{D}$ ' was a labor advisor concerned about the temporal pattern of employment. All utility values are for the 100 -year period shown in the figures, are scaled between 0 and 100 , and incorporate a $5 \%$ annual discount rate. The highest ranked policies for each decision maker are indicated by bold face. Quantitative comparisons among decision makers are not meaningful, although comparisons of policy ranks can be

\begin{tabular}{|c|c|c|c|c|c|}
\hline \multirow[t]{2}{*}{ Policy alternative } & \multirow{2}{*}{$\begin{array}{l}\text { Graph of } \\
\text { original } \\
\text { indicators }\end{array}$} & \multicolumn{4}{|c|}{$\begin{array}{l}\text { Total utility value for four } \\
\text { decision makers }\end{array}$} \\
\hline & & A & B & $\mathrm{C}$ & $\mathrm{D}$ \\
\hline Historical management & Fig. 16 & 97 & 75 & 84 & 31 \\
\hline Constrained Winkler-Dantzig & Fig. 17 & 89 & 67 & 82 & 33 \\
\hline Branch density hybrid & Fig. 18 & 84 & 78 & 71 & 32 \\
\hline Pit enhancement hybrid & Fig. 19 & 94 & 80 & 85 & 37 \\
\hline
\end{tabular}

dependencies among indicators were also assessed, with particular attention paid to elucidating attitudes towards risk and intertemporal trade-offs (Bell, 1977a). The result was a set of multi-attribute utility functions reflecting the preferences of the various participants (D.E. Bell, 1977b, and unpublished data).

The utility analyses have been used in the policy design studies to help articulate conflicting preferences, to provide objective functions for the optimization efforts, and to simplify comparisons of policies. These various roles are implicit in Table IV, where four of the policies developed earlier are evaluated according to the utility functions of four representative decision makers interviewed by D.E. Bell (personal communication, 1976).

The utility evaluations of Table IV are more concise than the original uncompressed indicators. When the set of policies is very large, the compressed utilities allow rapid identification of the more promising ones. Utilities also show where decision makers really differ in the policies they prefer.

As useful as the utility simplifications are, they have severe limitations. The technical constraints are discussed by Keeney and Raiffa (1976), but there are also problems posed by the limited experience of the decision maker.

In our studies, decision makers evaluated policy alternatives consistently only when the indicator values resembled those experienced historically. The decision makers had no "feel" for hypothetical alternatives far removed from their present experience, and attempts to compare such alternatives were therefore - literally - meaningless. Similar problems of "inconsis- 
tency" have been encountered in nearly every decision study dealing with radical alternatives (Liska, 1975).

Utility analysis presumes the existence of a comprehensive preference structure in the mind of the decision maker, and sets out to measure it. However, if meaningful preferences develop only on the basis of experience, then responses to the typical preference questions of utility analysis are more likely to reflect attributes of the question than those of the decision maker. This is precisely Lipset's (1976) finding in his retrospective analysis of public opinion surveys. Similarly, many decision studies have attributed difficulties in obtaining consistent responses to risk-taking questions to the fact that very few people have much self-conscious experience in assessing risks (e.g. Slovic and Lichtenstein, 1971).

A principal function of the policy design process is to develop meaning for a strategic range of alternative policies through the use of descriptive models and their performance indicators. This experience is a product, not a premise, of the design process. The appropriate language for most of that process will consist of carefully selected sets of indicators such as those in Figs. 16-19. Only in the latter stages - when meaning has been firmly established and simplification is desired - may it be useful to move to the highly stylized and compressed vocabulary of utility analysis.

Whether we employ utilities or simple indicators, the most profound difficulties of policy evaluation arise in attempts to deal with compression over time. The general inclination is to use various weighted averages of the indicator or utility streams (means, discounted sums, and so forth), but any time-averaging scheme necessarily implies a very particular attitude regarding the relation of present to future and the issue requires careful attention in the evaluation process.

Two time-related issues were particularly important in the budworm policy studies. The first and most novel concerned the problem of "local" time patterns. Several of the interviewed decision makers were adamant that their preference ratings for employment in one year depended upon employment levels in preceding and succeeding years. They further argued that their concern for the social dislocation induced by unemployment was such that fast rises in unemployment followed by slow drops were strongly preferred to slow rises followed by fast drops, regardless of the calendar years in which either pattern occurred. These positions made it impossible to apply any of the standard additive or multiplicative time aggregation formulae to the analysis, and also eliminated those existing approaches which permit restricted sorts of temporal interdependence (e.g. Fishburn, 1965; Meyer, 1970).

To do justice to the decision makers' stated preferences, Bell (1977a and b) found it necessary to develop a new method of deriving utility functions for time streams having inter-period dependencies. These analyses were applied where warranted in our policy evaluation work (e.g. the utility of person "D" in Table IV), and allowed subtle but significant distinctions to be made among complex indicator patterns of the sorts shown for employ- 
ment in Figs. 16-19. Equally important, the unrestrictive nature of this analytical framework forced the decision makers to articulate their own attitudes towards local time patterns of indicator behavior, and to confront the implications of those attitudes. This exploratory aspect of the evaluation process emphasizes our conviction that, when used at all, utility analysis must be tailored to express the stated preferences of the decision maker rather than the convenience of the analyst. The value of the exercise lies primarily in the dialogue between analyst and decision maker, not in the ultimate utility functions.

The second important temporal issue concerned questions of "absolute" time preferences - of trade-offs between the present and the future as such. The prescriptive aspect of the absolute time question has been debated for a very long time indeed, and its resolution is well beyond our presumption or competence (but see Samuelson (1976)). Even in the descriptive treatment of intertemporal preferences, however, we were immediately confronted with apparent contradictions.

When our studies began, the New Brunswick decision makers were employing cost-benefit analyses and requesting optimization studies which utilized 5\% annual discount rates for intertemporal indicator aggregation. This is not an uncommon figure in forest-related analyses (e.g. Goundry, 1960) and is apparently based upon the presumption that future returns from risky public projects should be discounted at rates equal to those at which guaranteed interest could be obtained from long-term government bonds (see Feldstein (1964) for an exploration of the curious logic underlying this idea). But when the same decision makers were asked choice questions to reveal their implicit intertemporal trade-off rates, a much different picture emerged. None of those interviewed expressed time preference rates of less than $10 \%$ per year, and most were closer to $20 \%$ (D.E. Bell, unpublished data). Similar results were gathered independently from several different sources and via several different questioning techniques. Discount rates of the order of $15-20 \%$ are rare in the resource management literature, but are commonly used by businessmen in assessing risky enterprises. The picture was further complicated when the same decision makers discounting the future at $20 \%$ per year simultaneously insisted on "maintaining a healthy, productive forest for posterity".

The comparative evaluation of policy alternatives is highly sensitive to the discount or intertemporal preference rates, as has been demonstrated by Fox and Herfindahl (1964). Given the highly varied responses to our time preference questions, it seemed inevitable that any array of temporally aggregated utility values such as that presented in Table IV would fail to reflect the decision makers' full range of concerns.

To ensure that meaning would not be lost in the quest for simplification, we chose to supplement the compressed utility values of Table IV with explicit representations of the undiscounted utility time streams. Figure 20 presents an example for several of the policies and one of the decision makers. 


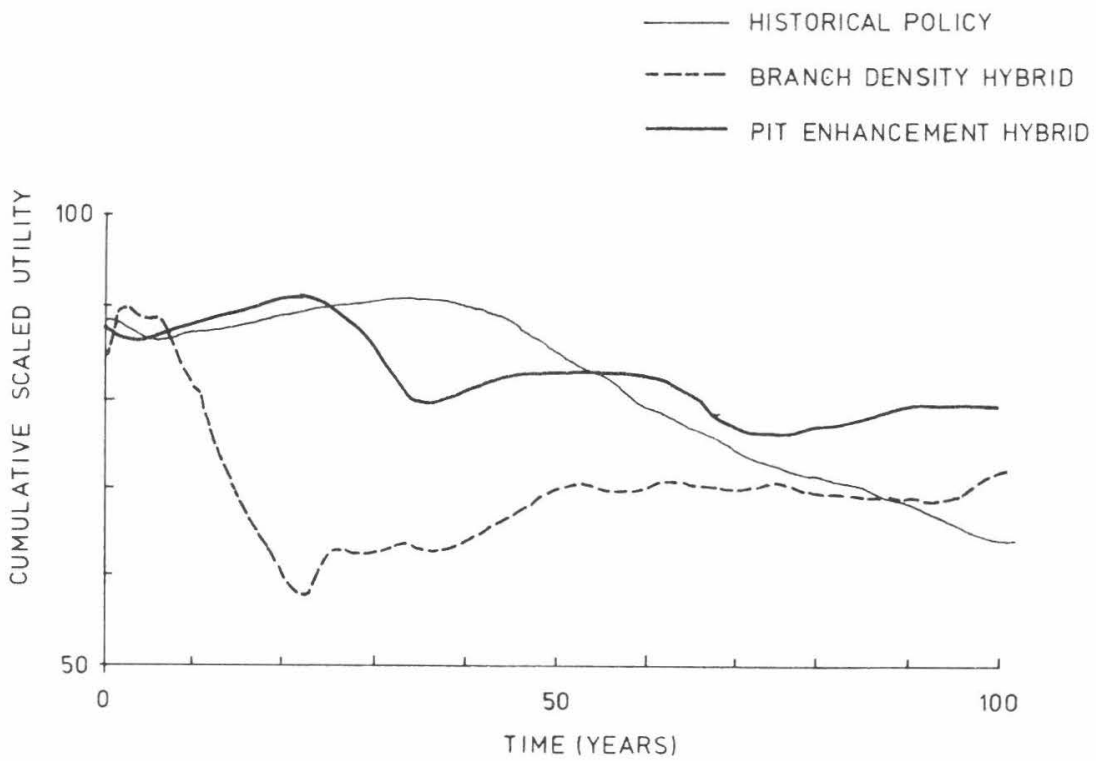

Fig. 20. Undiscounted utility time streams for decision maker $\mathrm{C}$ of Table IV. Utility value in year $(t)$ is cumulative utility to year $(t)$, scaled as the percent of the maximum possible utility in that year. Original evaluation indicators for the three policies shown were given in Figs. 16, 18 and 19.

Although the time patterns of Fig. 20 are more complex than the single values of Table IV, they also permit a direct examination of the relationships among utilities, discount rates and time horizons. The selection of a time preference rate is roughly equivalent to specifying a time horizon beyond which indicator behavior becomes largely irrelevant to the evaluation. For a plausible definition of irrelevance, this horizon might be 10 years for a $20 \%$ discount rate, about 20 years for $10 \%$, more than 40 years for $5 \%$ and, in principle, eternity for a zero discount rate.

It is clear from Fig. 20 that the rank order of policies is related to the time horizon or discount rate selected. Simply by changing from a 10 to a 40 to a 100 -year horizon, the identity of the highest ranked policy shifts from predation enhancement to historical approaches and back again. Regardless of what horizon a decision maker feels appropriate for his primary evaluation, we have found that the behavior of the utility or indicator trace in post-horizon periods is often used as an informal check to guarantee that short-term success has not been purchased at the price of "unacceptable" penalties in later years. This explicit use of utility (or individual indicator) time streams for evaluation is somewhat inelegant and in no way resolves the intertemporal aggregation issue. However, it has provided a relatively effective and unambiguous way of communicating the temporal implications of alternative policies to the decision maker. 
One final caveat is necessary. We argued earlier that the descriptive model must be explicitly bounded, and that attempts to be comprehensive were counter-productive and delusory. We suspect that the same is true for prescriptive evaluation work. In any case, the evaluation results presented here are in no sense comprehensive benefit-cost or social utility calculations. Such figures would necessarily include estimates of policy implementation costs, probabilities of succes and failure, and so on. Whatever their possible merits for ultimate questions of choice, these "total evaluations" carry an air of finality which make them comparatively sterile and premature elements for a process of adaptive policy design.

The primary goal of the evaluation process is not to define the best policy, but rather to create a foundation of experience and critical understanding upon which informed policy designs and meaningful choices can be based.

\section{COMMUNICATION, TRANSFER AND IMPLEMENTATION}

Myth: A focus on generality and transferability lays sufficient groundwork for policy implementation.

We have emphasized throughout that approaches to policy design need to be transferable to a wide variety of situations. But actual implementations are made under specific circumstances, not general ones. Decisions are shaped by local constraints, by particular institutional structures, and by unique personalities. A focus on generality sets the stage, but unless it is followed by effective application to specific situations the analysis is certain to remain a naive academic exercise.

Close working ties were maintained with decision makers, managers, and their scientific advisors throughout the budworm case study. Three levels of transfer and implementation are now being explored - one involving federal and provincial agencies in New Brunswick (Baskerville, 1976), one involving key institutions from other provinces and states, and one involving Japan and European countries faced with similar problems (Norton and Holling, 1977). Our goal is not to recommend a single policy. Rather, it is to transfer concepts, modeling and evaluation techniques, and a menu of policy alternatives to the hands of those responsible for and affected by decisions. In each case, the focus has been on information packages, communication techniques and transfer workshops which can be understood, controlled, and modified by the participants.

The study reported here began in 1972 with a 5-day workshop in New Brunswick that joined scientific and managerial expertise from federal and provincial agencies, together with modeling and analysis experience from the Institute of Resource Ecology, University of British Columbia. The results were a first crude simulation model and, more importantly, the identification of critical scientific, management, and policy issues needing further consideration (Walters and Peterman, 1974). These issues were further refined in a 
short but intensive feasibility study that culminated in serious commitments of time, personnel and resources by concerned institutions in New Brunswick.

Cooperative linkages between institutions and individuals are necessary but are not sufficient. Truly effective transfer and implementation hinge on the identification of local leadership - of an individual with judgment, perception, and the respect of research, management, and policy groups. In New Brunswick, that key individual was Dr. Gordon L. Baskerville (then of the Federal Department of the Environment and subsequently of the University of New Brunswick) who became a co-equal and guiding partner in this policy design project. Our experience in this and other activities strongly suggests that without a Baskerville on the receiving end, the panoply of models and techniques will serve the management community only as glass-cased display pieces.

Our initial activities were followed by an intensive effort to expand, refine and invalidate the model, and to test the usefulness of the policy design techniques reported in this paper. This multi-disciplinary work was of necessity a cooperative effort, involving at various times 15 scientists from Canada's Department of the Environment, the University of British Columbia's Institute of Resource Ecology and Vienna's International Institute for Applied Systems Analysis (Holling et al., 1976b). A key to the venture's success has been the willingness of a variety of research and grant administrators to support the concept of an institutional network and to gamble on a long-term project that they did not control. That network spread over half the world and amongst a variety of institutions, and was inherently incapable of offering much reassurance in the way of intermediate results. Without this sort of understanding and vigorous protection, nothing the research group could have done would have kept the program from being fragmented and aborted several times over.

The real test of our approach to policy design, and its foremost opportunity for payoff, came with the initiation of a phased series of implementation workshops which constituted an essential ingredient in the transfer process (Holling and Chambers, 1973; Walters, 1974; Holling, 1978). The first were technical workshops to transfer the descriptive and prescriptive models to the computer system in New Brunswick. This phase was judged complete when the scientists and managers there had the ability to independently run, critique, and alter the models in response to local needs and priorities. It should be obvious that no transfer worth speaking of can occur until this sort of expertise and confidence in model utilization develops in the management and policy groups.

Next followed a group of workshops designed to critique the analysis and to transfer the concepts, modeling approaches and a menu of policy alternatives. The first drew together forestry scientists, budworm experts and other entomologists from throughout the United States and Canada. The descriptive models were presented and critisized component by component. Alter- 
native hypotheses were defined, tentatively incorporated in the model, and interactively evaluated. Since the descriptive models had been defined from the start by the budworm researchers themselves, the model's residual uncertainties and approximations focused attention on critical areas for future field research. Tentative suggestions for restructuring scientific research priorities so as to be more responsive to overall system understanding were developed by the workshop participants and are summarized in Holling et al. (1975).

Subsequent workshops were held for the forest managers who will be responsible for implementing new policies, and others for the politicians, administrators and businessmen engaged in long-term policy development. Each set of workshops was followed by a period of careful review with modification to the models and design approach.

The major conclusions drawn from these transfer activities may be summarized as follows:

(1) Transfer means more than mailing the computer codes and writing a report. It also requires a program of workshops and intense "user" involvement so that the local scientists and managers end up as the real and acknowledged experts. A measure of success is the extent to which the original analysis group becomes less and less visible and the local groups more and more so as the program moves into implementation. The initiators' very strong and markedly parental inclinations to hold control too long must be resisted or transfer will fail.

(2) Vigorous institutional support and protection is necessary but not sufficient; the policy design approach can be transferred only to people, not departments. Respected local leadership of the program is necessary.

(3) The analysis must be made fully transparent and interactive. Hence the use of extensive graphical presentations (e.g. Peterman, 1975, 1977b) and an interactive computer environment which allows easy examination and modification of model assumptions. This lets cooperating scientists and managers explore their own experience and assumptions in the context of the models and is absolutely essential if a critical understanding of the strengths, weaknesses, and limitations of the analysis is to be achieved.

(4) Communication of the results must go beyond the traditional written forms. Modular slide-tape presentations describing the approach, the problem and the model can communicate the essential features vividly and rapidly without compromising content (Bunnell and Tait, 1974; Bunnell, 1976). A 4-minute motion picture of the space-time dynamics of Figs. 7 and 8 under various management regimes can better reveal that behavior than any amount of static discussion and analysis.

(5) A sequence of participatory workshops beginning with scientists, proceeding to managers, and finally involving policy makers builds a foundation of confidence and understanding on the part of all concerned. The reverse "top-down" sequence would force the technical analysis group into a prema- 
ture position of prominence, alienating local experts and promoting little but suspicion.

(6) The final - and perhaps the most restrictive - requirement of effective transfer is time. The budworm policy analysis per se took less than 6 months; the full program to implementation, more than 3 years. Some of this time was spent in the workshops described above, but much was literally an incubation period. A prerequisite for effective implementation seems to be time for the analysis group to appreciate the real options and constraints, time for the local managers and scientists to become truly conversant with new concepts, and time for the policy people to credit the analysis group with relevant intent. In retrospect, we doubt that the process could be rushed without fatally prejudicing the results in one way or another. Successful implementation requires patience (Pressman and Wildavsky, 1973; Bardach, 1976).

Responsible policy choices by the decision maker are based on understanding and control of, not necessarily belief in, the technical analysis. If such understanding is not clearly communicated, if such control is not effectively transferred, then mere technique subverts political judgment as a basis for public policy decisions, with no accountability for the results. That would simply be the promulgation of another undesirable myth - the one Lewis Mumford has called the Myth of the Machine - in systems analytic disguise (Weizenbaum, 1976).

A serious commitment to effective communication, transfer and implementation is the obligation of a responsible analysis group.

\section{CONCLUSIONS}

Major portions of the budworm case study took place while we were at the International Institute for Applied Systems Analysis. At the same time, various groups at that institute were engaged in studies of other resource development and environmental problems. This provided the opportunity to identify elements common to a wide range of problems. The projects chosen for the comparison included the forest pest problem described here, a study of national and international aspects of Pacific salmon management (Walters, $1975 b$ ) and an analysis of global energy problems (Haefele, 1976). These covered a broad range of contemporary dichotomies of management perspective - global versus regional, ecological and social versus physical and economic, national versus international. But they proved to share a perception of the primary issue (hypotheticality and coping with the unknown) and the central organizing concept (resilience topology). Surprisingly, and significantly, they also exhibited a similar structure of analytical steps (Fig. 21).

Any particular problem, whatever its reach, whatever its extent, can be conceptualized as occurring at a systems level embedded in a hierarchy. The system level of focus for each of the case studies is arbitrarily identified as level $N$ - the entry point for the analysis. We identify three essential steps 


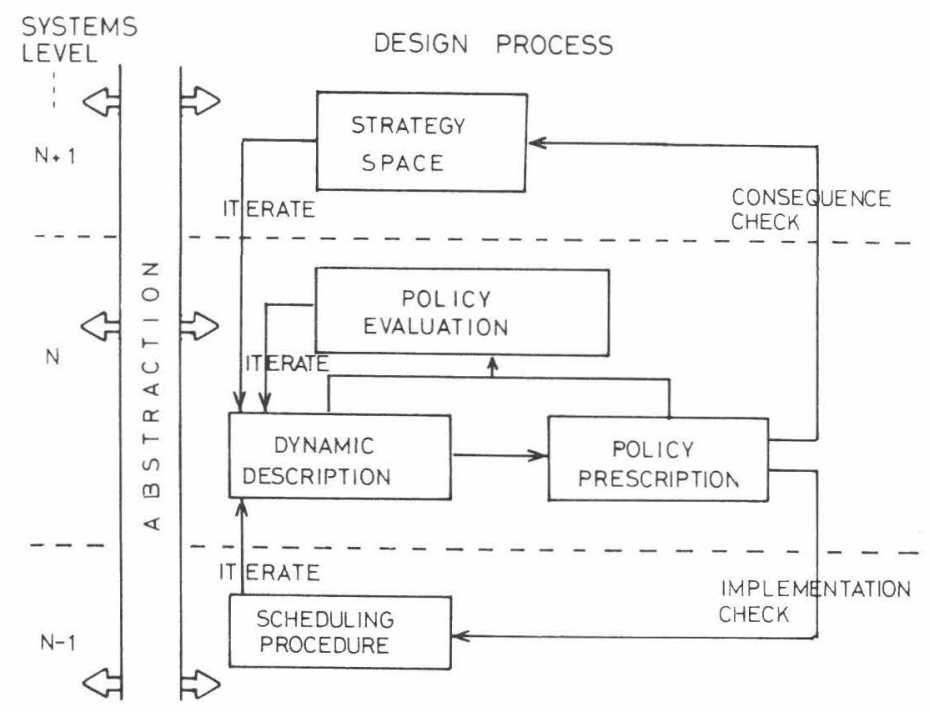

Fig. 21. The process of ecological policy design.

at this level: systems description, policy prescription, and policy evaluation. The systems description provides a detailed, dynamic description of the system for which management rules or policies are to be designed. At one point it seemed that this distinction was feasible only for ecological, physical, and other "natural" problems where "Mother Nature" was a given and could be objectively modeled. However, it became clear in the energy study that there existed the same need for a detailed dynamic description of societal interactions as they related directly to energy, capital and labor. Although the mathematical languages used in the descriptive models were different (simulation in the ecological studies and differential equations in the energy models), each case study demanded a model which could act as a kind of laboratory world for the development and evaluation of policies.

Descriptive models help to answer "what if" questions concerning the likely consequences of given policies or management acts. For these models to be used effectively it is necessary to identify alternative objectives and to design policies which will achieve them. This introduces the step of policy prescription - the techniques of articulating objectives and calculating "optimal" management rules and control laws. Typically, however, the combination of high dimensionality, nonlinearity and stochastic character of the descriptive models exceeds the computational limits of existing optimization techniques. Drastically simplified variants must be developed which accommodate the limitations of mathematical programming by judiciously sacrificing realism. These simplified "optimizations" generate useful probes into policy space but carry with them no guarantee of real-world "optimality" or even sensibility.

This leads us to the third step: policy evaluation. It deals in general with 
the comparison of alternative policies and in particular with checks on the sensitivity of policy to surprise, error and the unknown. The simplified "optimal" policies from the prescriptive studies are now evaluated within the complete descriptive model, paying particular attention to the generation of indicators relating to issues and processes omitted in the simplifications. The sensitivity, resilience, and robustness of these policies to the simplifying assumptions, to the omitted relationships, and to the residual uncertainty can be specifically tested and quantified.

These three basic analytic steps combine to produce a set of alternative policies evaluated in terms of a range of social objectives. But no matter how effective such an analysis, and at whatever level, it must be complemented by two more significant steps, both relating to the embedding of level " $N$ " within the overall hierarchy.

There is first the issue of execution and feasibility. Many otherwise admirable policies, when faced with specific limitations in capital and labor, and the constraints of institutional and political arrangements may be totally infeasible. A feasibility check at " $N-1$ " is therefore essential, and for this a new set of techniques and approaches that identify the sequential steps of practical implementation is necessary.

Just as there is a lower systems level, so there is a higher one $(N+1$ in Fig. 21). Inevitably, the policy analysis will leave out certain social, resource, and environmental values and considerations. The best solutions at the " $N$ " level can have disastrous consequences at " $N+1$ ". This higher level embedding poses difficult and critical issues which have as yet only been dealt with in a primitive but suggestive way (Haefele and Buerk, 1976). These, together with the related problems of explicit generation and measurement of systems resilience, define the present frontiers of the science of ecological policy design.

\section{ACKNOWLEDGMENTS}

In one sense it is presumptuous to thank those directly involved in this study since they were all co-equal partners in a strange inter-institutional and interdisciplinary experiment. Nevertheless, they deserve the recognition of being as much part of this creation as the authors of this paper. K.E.F. Watt provided much of the conceptual and methodological foundation for the study, as well as anticipating many of its results. The policy people and scientists of Canada's Department of the Environment gave remarkable and consistent support throughout. In particular, Gordon Baskerville, Charles Miller, and their colleagues of the Maritimes Forest Research Centre were committed partners in the team, with their flanks admirably protected by Evan Armstrong, Dick Belyea, Murray Nielson, Dick Prentice, and John Tener.

At the International Institute for Applied Systems Analysis, an astonishing group of outstanding people gave their all to something as silly as a bud- 
worm - David Bell, George Dantzig, Myron Bfiering, Carlos Winkler and Howard Raiffa.

The third institution in this effort was the Institute of Resource Ecology, University of British Columbia. Carl Walters, Ray Hilborn, Randall

Peterman, Sandra Buckingham and Jeff Stander developed the initial simulation model of the budworm system, and put their results and insights at our disposal. Along with Pille Bunnell, Nick Sonntag and Zafar Rashid they carved off pieces of the subsequent analysis and resolved them at times when they saw we were faltering. The unabashed enthusiasm and competence of Ralf Yorque contributed immeasurably to this project.

Finally, thanks are due Bob Fisher, Jery Stedinger and Warren Klein for independently reviewing the computer programs; Ted Foin, Neil Gilbert, Jack McLeod, Briar Mar, John Steele and Ken Watt for comments and suggestions on an earlier draft of this report; and Ulrike Hilborn for editing, drafting, and supervising its production.

\section{REFERENCES *}

Ackerman, B.A., Rose-Ackerman, S., Sawyer, J.W., Jr. and Henderson D.W., 1974. The Uncertain Search for Environmental Quality. Free Press, New York, N.Y., 386 pp.

Bardach, E., 1976. The Implementation Game. M.I.T. Press, Cambridge, Mass., 323 pp.

Baskerville, G.L., 1975 a. Spruce budworm: super silviculturist. For. Chron., 51 : 138-140.

Baskerville, G.L., 1975b. Spruce budworm: the answer is forest management - or is it? For. Chron., 51: 157-160.

Baskerville, G.L. (Editor), 1976. Report of the Task Force for Evaluation of Budworm Control Alternatives. Department of Natural Resources, Fredericton, N.B., 210 pp.

Bazykin, A.D., 1974. Volterra's system and the Michaelis-Menten equation. In: V.A. Ratner (Editor), Problems in Mathematical Genetics. U.S.S.R. Academy of Sciences, Novosibirsk (in Russian). (Available in English as: Structural and dynamic stability of model predator-prey systems. IIASA RM-76-8.)

Bell, D.E., 1977a. A utility function for time streams having interperiod dependencies. Oper. Res., 25: 448-458.

Bell, D.E., 1977b. A decision analysis of objectives for a forest pest problem. In: D.E. Bell, R. Keeney, and H. Raiffa (Editors), Conflicting Objectives in Decisions. Wiley, London, pp. 389-421.

Belyea, R. et al., 1975. The spruce budworm. For. Chron., 51: 135-160.

Blais, J.R., 1965. Spruce budworm outbreaks in the past three centuries in the Laurentide Park, Quebec. For. Sci., 11: 130-138.

\footnotetext{
* In an effort to make the bibliography as current as possible, we have cited many works presently available only as publications of the International Institute for Applied Systems Analysis (IIASA) and our own Institute of Resource Ecology (IRE). These may be obtained from the following addresses:

Documents and Publications, International Institute for Applied Systems Analysis, Schloss Laxenburg, A-2361 Laxenburg, Austria.

Publications (attn. Ralf Yorque), Institute of Resource Ecology, University of British Columbia, Vancouver, B.C., V6T 1W5, Canada.
} 
Blais, J.R., 1968. Regional variation in susceptibility of eastern North American forests to budworm attack based on history of outbreaks. For. Chron., 44:17-23.

Blais, J.R., 1974. The policy of keeping trees alive via spray operations may hasten the recurrence of spruce budworm outbreaks. For. Chron., 50: 19-21.

Branscomb, L.M., 1977. Science at the White House: a new start. Science, 196: 848-852.

Braybrooke, D. and Lindblom, C.E., 1963. A Strategy of Decision. Free Press, New York, N.Y. 268 pp.

Brewer, G., 1973. The Politician, the Bureaucrat, and the Consultant. Basic Books, New York, N.Y., $291 \mathrm{pp.}$

Brown, C.E., 1970. A Cartographic Representation of Spruce Budworm Choristoneura fumiferana (Clem.), Infestation in Eastern Canada, 1909-1966. Canadian Forestry Service Publication No. 1263.

Bunnell, P., 1976. The Spruce Budworm: an Ecosystem Problem and a Modeling Approach to its Management. An eight-part slide-tape presentation ( $80 \mathrm{~min}$ ). Institute of Resource Ecology, Vancouver, B.C.

Bunnell, P. and Tait, D., 1974. A Primer on Models: Why and How. A five-part slide-tape presentation ( 280 slides, $50 \mathrm{~min}$ ). Institute of Resource Ecology. Vancouver, B.C.

Canada, Department of the Environment. 1938-1976. Forest Insect and Disease Survey Annual Reports. (Author varies.)

Clark, W.C., 1976. Mathematical Bioeconomics. Wiley, New York, N.Y., 352 pp.

Clark, W.C. and Holling, C.S., 1979. Process models, equilibrium structures, and population dynamics: on the formulation and testing of realistic theory in ecology. In: U. Halbach and J. Jacobs (Editors), Population Ecology. Fortschrifte der Zoologie. 6. Fischer Verlag, Stuttgart, in press.

Cline, R., 1961. A Survey and Summary of Mathematical and Simulation Models as Applied to Weapon System Evaluation. ASD Technical Report 61-376.

Conway, G.R., Norton, G.A., King, A.B.S. and Small, N.J., 1975. A systems approach to the control of the sugar cane frog hopper. In: G.E. Dalton (Editor), Study of Agricultural Systems. Applied Science, London, pp. 193-229.

Crocker, J.F.S., Ozere, R.L., Safe, S.H., Digout, S.C., Rozee, K.R. and Hutzinger, O., 1976. Lethal interaction of ubiquitous insecticide carriers with virus. Science, 192: 1351-1353.

Davidson, A.G. and Prentice, R.M. (Editors), 1967. Important Forest Insects and Diseases of Mutual Concern to Canada, the United States and Mexico. Department of Forestry and Rural Development, Canada, 248 pp.

Elliot, K.R., 1960. A history of recent infestations of the spruce budworm in northeastern Ontario, and an estimate of resultant timber losses. For. Chron., 36: 61-82.

Feldstein, M.S., 1964. The social time preference discount rate in cost-benefit analysis. Econ. J., 74: 360-379.

Fiering, M.B. and Stedinger, J., 1976. Progress report on budworm optimization efforts. Harvard University Division of Engineering and Applied Physics, Harvard, Ill., unpublished.

Fishburn, P.C., 1965. Markovian dependence with whole product sets. Oper. Res., 13: $238-257$.

Fox, I.K. and Herfindahl, O.C., 1964. Attainment of efficiency in satisfying demands for water resources. Am. Econ. Rev., 1964: 198-206.

Goundry, G.K., 1960. Forest management and the theory of capital. Can. J. Econ., 26: 439-451.

Greenbank, D.O., 1957. The role of climate and dispersal in the initiation of outbreaks of the spruce budworm in New Brunswick. 2. The role of dispersal. Can. J. Zoology, 35: 385-403.

Greenbank, D.O., 1973. The Dispersal Process of Spruce Budworm Moths. Canadian Forestry Service, Maritimes Forest Research Centre Information Report M-X-39. 
Gutierrez, A.P., Demichele, D.W. and Wang, Y., 1977. New systems technology for cotton production and pest management. Proc. 15th Int. Congr. Entomol., pp. 553-559.

Haefele, W., 1974. Hypotheticality and the new challenges: the pathfinder role of nuclear energy. Minerva, 10: 303-323.

Haefele, W. and Buerk, R., 1976. An Attempt of Long-range Macroeconomic Modeling in View of Structural and Technological Change. IIASA RM-76-32.

Haefele, W., 1976. Second Status Report of the IIASA Project on Energy Systems 1975. IIASA RR-76-1, 249 pp.

Hilborn, R., Holling, C.S. and Walters, C.J., 1976. Managing the unknown: approaches to ecological policy design. In: J.J. Riesa (Editor), Biological Evaluation of Environmental Impact. President's Council on Environmental Quality, in press.

Holcomb Research Institute, 1976. Environmental Modeling and Decision Making. Praeger, N.Y., 162 pp.

Holling, C.S., 1965. The functional response of predators to prey density and its role in mimicry and population regulation. Mem. Entomol. Soc. Can., 45: 1-60.

Holling, C.S., 1973. Resilience and stability of ecological systems. Ann. Rev. Ecol. Syst., 4: $1-23$.

Holling, C.S., 1976. Resilience and stability of ecosystems. In: E. Jantsch and C.H. Waddington (Editors), Evolution and Consciousness: Human Systems in Transition. AddisonWesley, Reading, Mass., pp. 73-92.

Holling, C.S. (Editor), 1978. Adaptive Environmental Assessment and Management. Wiley, Chichester, $377 \mathrm{pp}$.

Holling, C.S. and Buckingham, S., 1976. A behavioral model of predator-prey functional responses. Behav. Sci., 21: 183-195.

Holling, C.S. and Chambers, A.D., 1973. Resource science: the nurture of an infant. BioScience, 23: 13-20.

Holling, C.S. and Clark, W.C., 1975. Notes towards a science of ecological management. In: W.H. van Dobben and R.H. McConnell (Editors), Unifying Concepts in Ecology. W. Junk, The Hague, pp. 247-251.

Holling, C.S. and Dantzig, G.B., 1977. Determining Optimal Policies for Ecosystems. IRE Research Report R-7-B, $41 \mathrm{pp}$.

Holling, C.S. and Goldberg, M.A., 1971. Ecology and planning. J. Am. Inst. Planners, 37 : 221-230.

Holling, C.S., Jones, D.D. and Clark, W.C., 1975. Spruce Budworm/Forest Management. IRE Workshop Progress Report PR-5, 50 pp.

Holling, C.S., Huang, C.C. and Vertinsky, I. 1976a. Technological change and resource flow alignments: an investigation of systems growth under alternative funding/feedback. Berlin: Int. Inst. of Management, I 76/19, 34 pp.

Holling, C.S., Jones, D.D. and Clark, W.C., 1976b. Ecological policy design: a case study of forest and pest management. IIASA Conference 1976. Vol. 1, pp. 139-158.

Holling, C.S., Jones, D.D. and Clark, W.C., 1979. Meager data and the analysis of ecological processes: predation. Unpublished.

Jones, D.D., 1975. The application of catastrophe theory to ecological systems. In: G.S. Innis (Editor), New Directions in the Analysis of Ecological Systems, Part 2. Simulation Councils, Inc., La Jolla, Calif., pp. 133-148. (Reprinted in Simulation, 29 (1977) 1-15.)

Keeney, R. and Raiffa, H., 1976. Decisions with Multiple Objectives. Wiley, New York, N.Y., 569 pp.

Kiritani, K., 1977. Systems approach for management of rice pests. Proc. 15 th Int. Congr. Entomol., pp. 591-598.

Lipset, S.M., 1976. The wavering polls. Publ. Interest, 43: 70-89.

Liska, A.E. (Editor), 1975. The Consistency Controversy: Readings on the Impact of Attitude on Behavior. Halsted Press, New York, N.Y., 324 pp. 
Loucks, O.L., 1962. A forest classification for the Maritime Provinces. Proc. N.S. Inst. Sci., 25: 85-167.

Ludwig, D., Jones, D.D. and Holling, C.S., 1978. Qualitative analysis of insect outbreak systems: the spruce budworm and forest. J. Anim. Ecol., 47: 315-332.

Mar, B.W., 1974. Problems encountered in multi-disciplinary resources and environmental simulation models development. J. Environ. Manage., 2: 83-100.

Meyer, R.F., 1970. The utility of assets in an uncertain but time invariant world. In: J. Lawrence (Editor), OR69: Proc. 5th Int. Conf. Oper. Res. Tavistock, London, pp. 627-648.

Miller, C.A. and Ketella, E.G., 1975. Aerial control operations against the spruce budworm in New Brunswick, 1952-1973. In: M.L. Prebble (Editor), Aerial Control of Forest Insects in Canada. Department of the Environment, Ottawa, Ont.

Mitchell, R., Mayer, R.A. and Downhower, J., 1976. An evaluation of three biome programs. Science, 192: 859-865.

Morris, R.F., 1963. The dynamics of epidemic spruce budworm populations. Mem. Entomol. Soc. Can. No. 31.

Norton, G. and Holling, C.S., (Editors), 1977. Proceedings of a Conference on Pest Management. IIASA CP-77-6, 352 pp.

Noy-Meir, I., 1975. Stability of grazing systems: an application of predator-prey graphs. J. Ecol., 63: 459-481.

Pearce, P.A., 1975. Effects on birds. In: M.L. Prebble (Editor), Aerial Control of Forest Insects in Canada. Department of the Environment, Ottawa, Ont., pp. 306-313.

Pearce, P.A., Peakall, D.B. and Erskine, A.J., 1976. Impact on forest birds of the 1975 spruce budworm spay operation in New Brunswick. Canadian Wildlife Service Progress Notes No. 62., 7 pp.

Peterman, R.M., 1975. New techniques for policy evaluation in ecological systems; methodology for a case study of Pacific salmon fisheries. J. Fish. Res. Board Can., 32: 2179-2188.

Peterman, R.M., 1977a. A simple mechanism which causes collapsing stability regions in exploited salmonid populations. J. Fish. Res. Board Can., 34: 1130-1142.

Peterman, R.M., 1977b. Graphical evaluation of environmental management options: examples from a forest-insect pest system. Ecol. Modelling, 3: 133-148.

Prebble, M.L. (Editor), 1975. Aerial Control of Forest Insects in Canada. Department of the Environment, Ottawa, Ont., 330 pp.

Pressman, J.L. and Wildavsky, A., 1973. Implementation: how Great Expectations in Washington are Dashed in Oakland. University of California Press, Berkeley, Calif.

Ricker, W.E., 1954. Stock and recruitment. J. Fish. Res. Board Can., 11: 559-623.

Ricker, W.E., 1963. Big effects from small causes: two examples from fish population dynamics. J. Fish. Res. Board Can., 20: 257-264.

Samuelson, P.A., 1976. Economics of forestry in an evolving society. Econ. Inquiry, 14: 466-492.

Shubik, M. and Brewer, G., 1972. Models, Simulation, and Games - a Survey. Rand Report R-1060-ARPA/RC.

Slovic, P. and Lichtenstein, S., 1971. Comparison of Bayesian and regression approaches to the study of information processing in judgment. Organizational Behav. Human Performance, 6: 649-744.

Southwood, T.R.E., 1976. Bionomic strategies and population parameters. In: R.M. May (Editor), Theoretical Ecology: Principles and Applications. Blackwells Scientific, Oxford, pp. 26-48.

Stedinger, J., 1977. Spruce Budworm Management Models. Thesis, Harvard University, Harvard, Mass., 351 pp., mimeographed.

Takahasi, F., 1964. Reproduction curve with two equilibrium points: a consideration on the fluctuation of insect population. Res. Popul. Ecol., 6: 26-36. 
Thom, R., 1975. Structural Stability and Morphogenesis: An Outline of a General Theory of Models. Benjamin, Reading, Mass.

Walters, C.J., 1974. An interdisciplinary approach to development of watershed simulation models. Technological Forecasting and Social Change, 6: 299-323.

Walters, C.J., 1975a. Foreclosure of options in sequential resource development decisions. IIASA RR-75-12.

Walters, C.J. (Editor) 1975b. Proceedings of a workshop on salmon management. IIASA CP-75-2.

Walters, C.J. and Hilborn, R., 1976. Adaptive control of fishing systems. J. Fish. Res. Bd. Can., 33: 145-159.

Walters, C.J. and Peterman, R.M., 1974. A systems approach to the dynamics of spruce budworm in New Brunswick. Quaestions entomologicae, 10: 177-186.

Watt, K.E.F., 1963. Dynamic Programming, "Look Ahead Programming", and the Strategy of Insect Pest Control. Can. Ent., 95: 525-536.

Webb, F.E., Blais, J.R. and Nash, R.N., 1961. A cartographic history of spruce budworm outbreaks and aerial forest spraying in the Atlantic region of North America 1948-59. Can. Ent., 93: 360-379.

Weizenbaum, J., 1976. Computer power and human reason. Freeman, San Francisco, Calif.

Winkler, C., 1975. An optimization technique for the budworm forest-pest model. IIASA RM-75-11.

Yorque, R., Baskerville, G., Clark, W.C., Holling, C.S., Jones, D.D. and Miller, C.A. Forthcoming. Ecological policy design: a case study of forests, insects, and managers. 

